\title{
Diversity, Ecology, and Prevalence of Antimicrobials in Nature
}

\author{
Megan M. Mullis', Ian M. Rambo², Brett J. Baker ${ }^{2}$ and Brandi Kiel Reese ${ }^{\text {1* }}$ \\ ${ }^{1}$ Department of Life Sciences, Texas A\&M University Corpus Christi, Corpus Christi, TX, United States, ${ }^{2}$ Department of \\ Marine Science, University of Texas Marine Science Institute, Port Aransas, TX, United States
}

OPEN ACCESS

Edited by:

Daniela Ceccarelli,

European Commission,

Belgium

Reviewed by:

Marinella Silva Laport,

Federal University of Rio

de Janeiro, Brazil

Polpass Arul Jose,

The Hebrew University of

Jerusalem, Israel

*Correspondence:

Brandi Kiel Reese

brandi.reese@tamucc.edu

Specialty section:

This article was submitted to

Antimicrobials, Resistance and

Chemotherapy,

a section of the journal

Frontiers in Microbiology

Received: 01 July 2019

Accepted: 18 October 2019

Published: 14 November 2019

Citation:

Mullis MM, Rambo IM, Baker BJ and Reese BK (2019) Diversity,

Ecology, and Prevalence of Antimicrobials in Nature.

Front. Microbiol. 10:2518.

doi: 10.3389/fmicb.2019.02518
Microorganisms possess a variety of survival mechanisms, including the production of antimicrobials that function to kill and/or inhibit the growth of competing microorganisms. Studies of antimicrobial production have largely been driven by the medical community in response to the rise in antibiotic-resistant microorganisms and have involved isolated pure cultures under artificial laboratory conditions neglecting the important ecological roles of these compounds. The search for new natural products has extended to biofilms, soil, oceans, coral reefs, and shallow coastal sediments; however, the marine deep subsurface biosphere may be an untapped repository for novel antimicrobial discovery. Uniquely, prokaryotic survival in energy-limited extreme environments force microbial populations to either adapt their metabolism to outcompete or produce novel antimicrobials that inhibit competition. For example, subsurface sediments could yield novel antimicrobial genes, while at the same time answering important ecological questions about the microbial community.

Keywords: antimicrobial, PKS, NRPS, competition, subsurface, diversity

\section{INTRODUCTION}

Microbes play fundamental roles in ecosystem functioning, particularly through mediating biogeochemical cycles, yet we know very little about their interactions in nature. Microorganisms have several mechanisms for survival depending on the respective environment: (1) outcompete neighboring populations through adaptation and/or evolution; (2) work with their neighbors via mutualistic cooperation; and/or (3) inhibit or kill their neighbors. One of the most common mechanisms for inhibition or elimination of competition is the production of antimicrobial compounds, including antibacterials and antifungals. These compounds can be toxic to the surrounding community, providing a selective advantage for nutrients, carbon, and space (Bibb, 2005; Rigali et al., 2008). Many environments have been explored for novel antimicrobial discovery including continental soils (Wright, 1956; Gottlieb, 1976; Chander et al., 2005; Bundale et al., 2015), caves (Cheeptham and Saiz-Jimenez, 2015), desert soils (Hozzein et al., 2011; El-Deeb et al., 2013; Nithya et al., 2015; Ouchari et al., 2019), freshwater sediments and water (Cross, 1981; Cannell et al., 1988; Madhumathi et al., 2011), and marine sediments and water (Duff et al., 1966; Martins et al., 2008; Valli et al., 2012; Bose et al., 2015; Zinke et al., 2017; Quintero et al., 2018; Ser et al., 2018; Hook and Plante, 2019; Skočibušić et al., 2019). Terrestrial areas including soils, deserts, and freshwater lakes and rivers are typically easier to access relative to deep-sea environments and generate promising results in the hunt for antimicrobial activity, as natural products isolated from these environments have been used medicinally (Mcdonald et al., 1996; Haefner, 2003; Hughes et al., 2008; Dias et al., 2012; David et al., 2015). However, one of the most diverse 
biomes on our planet has yet to be examined for antimicrobial production: the marine deep subsurface biosphere.

This review will survey natural antimicrobials that have been isolated from Bacteria and putative antimicrobial production within different environments including continental soil, caves, freshwater, marine, and deep subsurface sediments. Key studies focusing on specific genes for antimicrobial production within these environments will be discussed. Notably absent from this review is fungal antibiotic discovery in ecosystems other than terrestrial soils, which would necessitate an entire review on its own. The overall purpose of this review is to highlight studies that have found natural antimicrobial producing genes from Bacteria and Archaea within various environments, as well as pinpoint areas that have yet to be explored.

\section{HISTORY OF ANTIMICROBIAL DISCOVERY}

The production of an antimicrobial by a microorganism was first noted in the fungus Penicillium chrysogenum in 1929 by Alexander Fleming (Shama, 2009; Bush, 2010). This critical observation initiated the discovery and isolation of penicillin in the early 1940s, spurring a "Golden Age" of antimicrobial discovery from 1940 to 1980 (Figure 1), which led to a boom in the exploration, isolation, and commercialization of natural products from cultivated continental microorganisms (Mehta et al., 2006; Katz and Baltz, 2016). This Golden Age yielded natural products including biopharmaceutical primary and secondary metabolites, such as macrolides, quinolones, tetracyclines, and cephalosporins as well as chemical derivatives that combat bacteria, fungi, and eukaryotic parasites (Harvey, 2008) by inhibiting the synthesis of cell walls, proteins, DNA, or metabolites essential for cellular functions (Walsh, 2000). The initial compounds isolated from microorganisms during the Golden Age were from soils around the world including the United States, Russia, Borneo, and the Philippines (Raper et al., 1944; Hays et al., 1945; Wells, 1952; Abraham, 1962; Kaplan and Weinstein, 1968; Rubin and Tamaoki, 2000; Andersson and MacGowan, 2003; Emmerson and Jones, 2003; Grabowski, 2005; Moellering, 2006; Houbraken et al., 2011; Chander et al., 2015; Ventola, 2015; Gradnigo et al., 2016; Kim et al., 2018). After the discovery of carbapenems in 1976, antimicrobial bioprospecting from Streptomyces cattleya tapered off and has since been limited to artificial synthesis and rediscovery (Figure 1; Williamson et al., 1985; Drews, 2000; Aminov, 2009).

Traditionally testing for antimicrobial production relied on agar plate cultivation and identifying zones of inhibition caused by competing Bacteria (Schatz et al., 1944; Mehta et al., 2006; Lewis, 2013). Antimicrobial compounds are naturally produced as secondary metabolites from microorganisms as a defense mechanism. Microorganisms can use various methods to defend themselves from harm including producing toxins such as antimicrobial compounds that act against surrounding microbial cells. As a result, microorganisms exposed to natural products with toxic effects can develop strategies for antimicrobial resistance (Cohen, 1992; Tenover, 2006), which are observed relatively quickly in microorganisms due to horizontal gene transfer (Read and Woods, 2014). Naturally-produced antimicrobials and antimicrobial resistance have co-evolved within microbial communities by eliminating susceptible strains, leaving behind those that have resistance or become resistant (Kerr et al., 2002; Ventola, 2015). This means that the method of culturing Bacteria to identify and isolate bioactive compounds often results in the re-discovery of known compounds, which is expensive and time consuming (Machado et al., 2015). However,

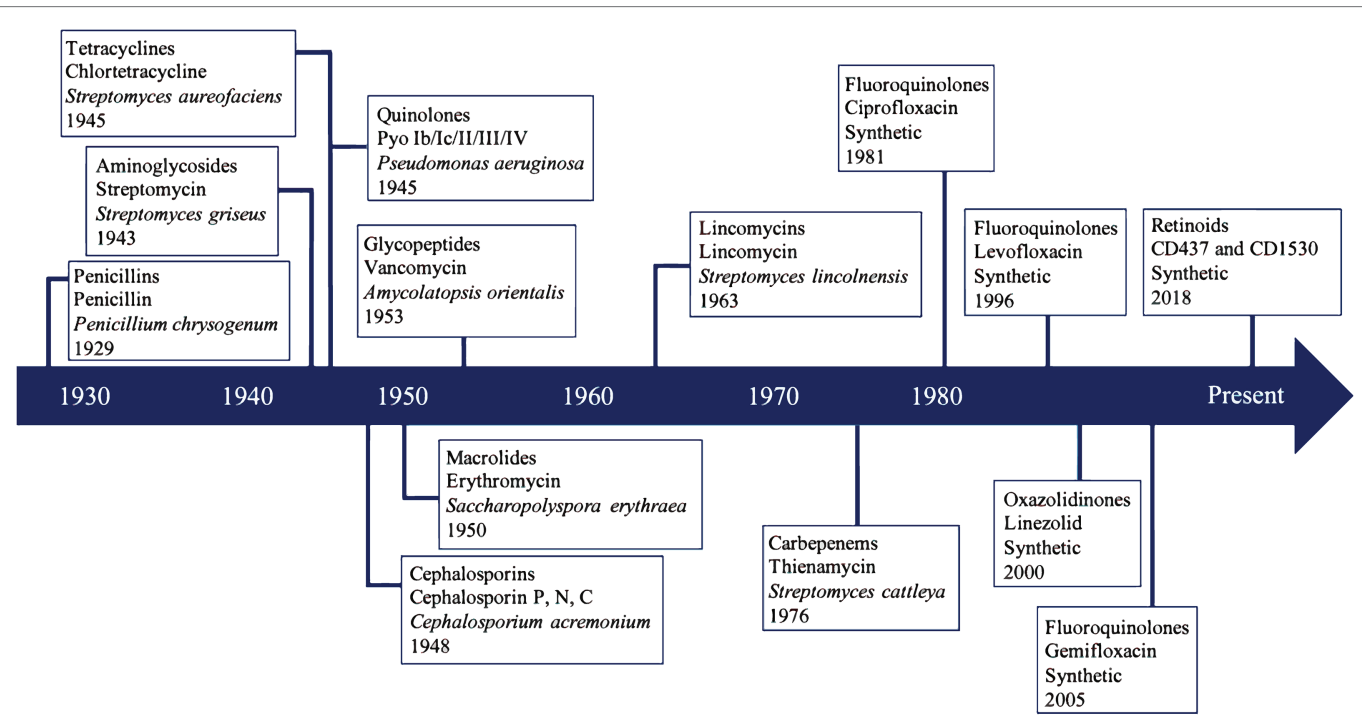

FIGURE 1 | Discovery timeline of most clinically important antibiotic classes and first isolated antibiotic compound. Each box contains the class of antibiotics, the first compound isolated, the organism that naturally produced the compound, and the isolation year. 
computational methods for assessing secondary metabolite production potential can complement, or in some cases replace, traditional exploration techniques (Culligan et al., 2014; Adu-Oppong et al., 2017).

\section{POLYKETIDE SYNTHASE AND NONRIBOSOMAL PEPTIDE SYNTHASE GENE STRUCTURE AND FUNCTION}

Antimicrobial production occurs through a multitude of metabolic intermediate biosynthesis pathways, with two of the most common and extensively researched protein families involved in these processes being the polyketide synthases (PKS) and non-ribosomal peptide synthases (NRPS) (Ehrenreich et al., 2005). PKSs synthesize polyketides, a broad class of bioactive compounds defined by alternating carbonyl and methylene groups (Staunton and Weissman, 2001), while NRPSs produce peptides independent of messenger RNA and ribosomal machinery (Walsh, 2016). PKSs and NRPSs exhibit high structural and functional similarity and have been found to form hybrid genes producing antimicrobial compounds (Fisch, 2013). These genes are generally organized into operons or gene clusters generally ranging from $1 \mathrm{~kb}$ to greater than $10 \mathrm{~kb}$ in length (Medema et al., 2015) which encode large, multifunctional enzymes (200-2,000 kDa) (Ehrenreich et al., 2005). PKSs and NRPSs can synthesize other biologically active compounds such as siderophores and immunosuppressants (Cane and Walsh, 1999; Crosa and Walsh, 2002; Ehrenreich et al., 2005). These enzymes are classified according to their structure and biosynthetic function.

There are three types of naturally occurring PKS modules, aptly designated Type I, II, and III (Shen, 2003). Type I is composed of large enzymes that contain multiple functional domains with defined functions that perform a single catalytic step during biosynthesis of the antimicrobial compound. The Type II PKS complex includes several single-module proteins with separated enzymatic activities acting repetitively to produce a polyketide. Type III consists of a single active site enzyme that acts iteratively to form the final polyketide product (Austin and Noel, 2003; Weissman, 2009). Type I is most common in Bacteria, Type II is most commonly found in fungi, and Type III is most common within plants (Yu et al., 2012). Type I and II PKS genes will receive focus in this review.

There are approximately 10 domains that contribute to the PKS gene. Three essential domains are necessary for the PKS operon to function, which include $\beta$-ketosynthase (KS), acyltransferase (AT), and acyl carrier protein domains (ACP) (Ansari et al., 2004). The KS domain functions via the attachment of a malonyl-CoA extender unit to an acetyl-CoA starter molecule. The AT domain serves as a support to load the appropriate substrate onto the enzyme, whereas the ACP domain supervises the movement of substrates and products between the different active sites of the enzyme. Variability of antimicrobial compounds produced via the PKS pathway is due to insertion or deletion of optional domains, including $\beta$-ketoreductase, dehydratase, and trans-acting enoyl (Cane and Walsh, 1999). If all three of these optional domains are present, then the PKS gene is highly reducing, otherwise it is non-reducing (Ma et al., 2009; Gallo et al., 2013; Liu et al., 2015). This determination of highly-reducing versus non-reducing is due to the presence of domains that can reduce and/or dehydrate substrates to construct a specific compound (Chiang et al., 2010). PKS genes can be deemed partially-reducing if the $\beta$-ketoreductase and dehydratase domains are present and the trans-acting enoyl domain is not. There are other optional domains that are less prevalent than those described. Non-reducing PKS genes have a special domain located in at the N-terminus called the starter unit acyl carrier protein transacylase, which is responsible for selection and loading of a starter unit and the product template. The product template domain controls the folding of the polyketide backbone (Gallo et al., 2013).

The NRPS gene encodes multifunctional enzymes whose modules elongate the amino acid chain (Staunton and Weissman, 2001). Similar to the PKS gene, there are three essential domains required for the function of this gene. They include the adenylation (A), thiolation/peptidyl carrier protein (T/PCP), and condensation domains (C) (Weissman and Müller, 2008; Weissman, 2015). The A domain recognizes and activates the related amino acid or hydroxyl acid. The T/PCP domain functions as a "swinging arm" carrying a phosphopantetheinyl at a conserved serine residue and delivers substrates to the corresponding active site of the domain. The $\mathrm{C}$ domain catalyzes the peptide bond formation between the activated amino acid and elongation chain (Weissman, 2015). There are optional domains associated with NRPSs as well, such as the epimerization, reductase, cyclization, and oxidation domains (Gallo et al., 2013). It has been proposed that NRPSs can be sorted into three groups: linear, iterative, and non-linear (Mootz et al., 2002; Eisfeld, 2009). Linear NRPSs follow a specific template of domain organization and can be predicted (Eisfeld, 2009). Iterative NRPSs are similar to linear NRPSs but use some domains repeatedly during biosynthesis. These NRPSs are more common with fungi and are better described due to predictability (Keller et al., 2005; Medema et al., 2011; Röttig et al., 2011). Non-linear NRPSs have more complex domain interactions and the possible product created cannot be predicted (Mootz et al., 2002). The inability to predict non-linear NRPS products is due to the capability to utilize free soluble molecules during biosynthesis (Eisfeld, 2009).

Hybrid PKS-NRPSs have been found to be structurally and functionally diverse across bacteria (Wenzel and Müller, 2005a,b; Fisch, 2013). Microbial hybrid PKS-NRPSs are formed commonly in nature by adjoining the PKS modules and NRPS modules together in an 'assembly line' fashion (Fisch, 2013). The functionality of the hybrid depends on the domain organization within each module. The organization of the domains within each module results in a specific cascade of enzymatic reactions that give rise to diverse hybrid antimicrobials such as bleomycin (Du et al., 2000), epothilone (Tang et al., 2000), yersiniabactin (Pelludat et al., 1998), and rapamycin (Aparicio et al., 1996; Boettger and Hertweck, 2013; Masschelein et al., 2013).

Both PKS and NRPS pathways are diverse due to the variable domains that can be present or absent in a specific order following the essential domains (Figure 2; Cane and Walsh, 1999). The order, presence, absence, and essential domains are critical to what antimicrobial molecule is created. 


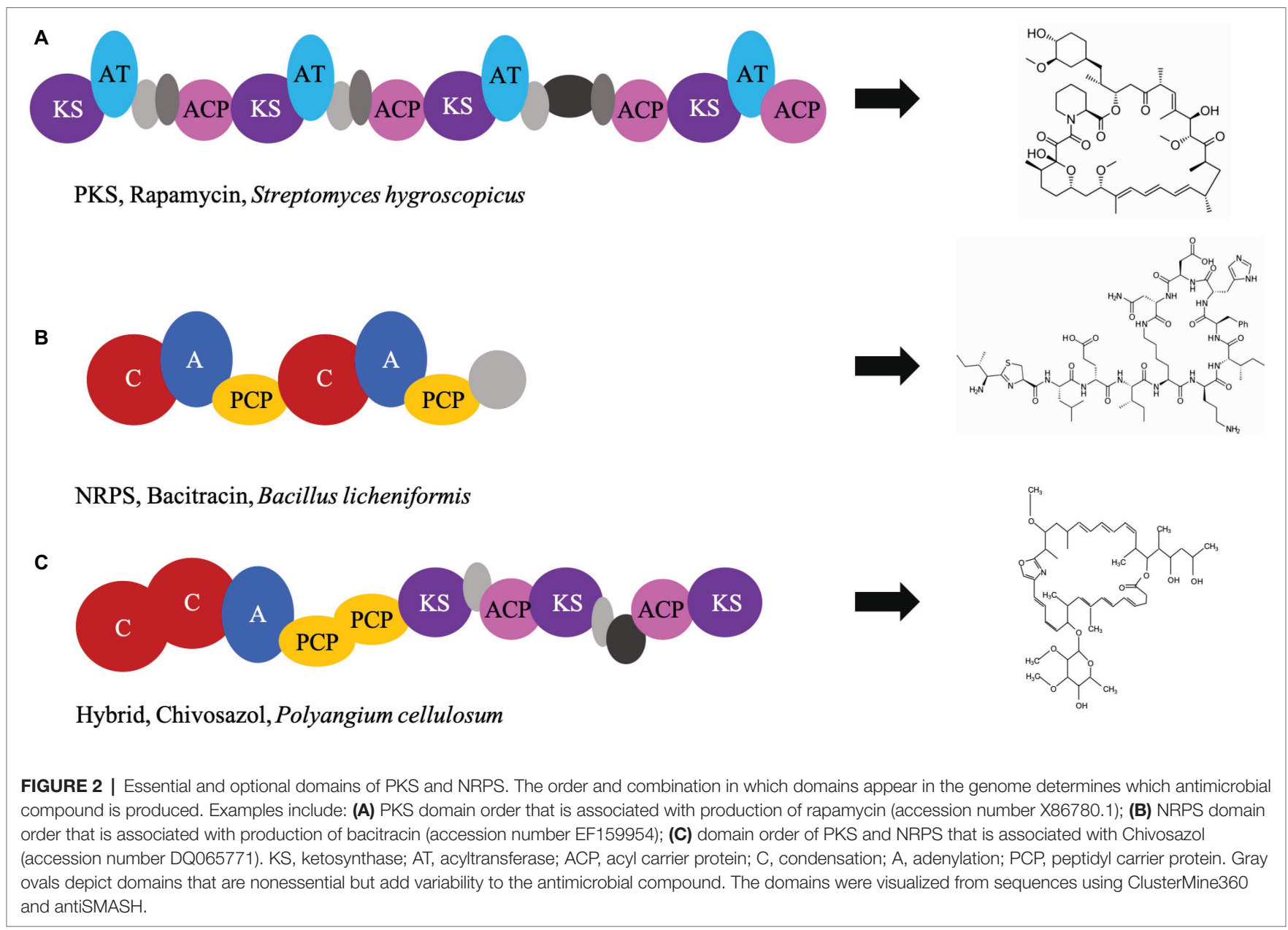

Due to the large size and complexity of antimicrobial gene clusters, it is difficult to target the entire antimicrobial gene for identification and isolation (Weissman, 2015; Ziemert et al., 2016). However, the identification, isolation, and availability of essential domain sequences in public databases have aided further annotation of homologous domains of these megasynthases through bioinformatic data mining (Keller et al., 2005; Bergmann et al., 2007; Khaldi et al., 2010; Weber et al., 2015). Despite these recent advances, only a few studies exist that explore these genes in an ecological context (Helfrich et al., 2014; Tyc et al., 2017).

\section{COMPUTATIONAL APPROACHES TO DISCOVERY}

Limitations in culture-based techniques have brought computational genomic mining methods to the forefront of antimicrobial exploration (Banik and Brady, 2010; Juhas et al., 2011). Advances in DNA sequencing technologies and computational approaches have become increasingly prevalent since the early 2000s as a means of exploration and prediction of antimicrobial production potential (Van Lanen and Shen, 2006; Li and Vederas, 2009; Zerikly and Challis, 2009; Harvey et al., 2015). The study of "omics includes analysis of molecules" roles, actions, and relationships within a cell (Patti et al., 2012) to determine a microorganisms' genetical potential and activity within its respective environment. The significantly decreased cost of DNA sequencing in the past decade has led to the creation of massive genomic databases (Shendure et al., 2017), with a recent explosion of environmental genomes reconstructed through metagenomic (community genetic potential, DNA) sequencing and binning methods that represent novel, and often unculturable, taxonomic lineages (Hug et al., 2016). Other 'omics' technologies are utilized in secondary metabolite prospecting, including metatranscriptomics (actively expressed genetic material, RNA), metaproteomics (entirety of proteins), and metabolomics (entirety of metabolites) (Zhang et al., 2010; Franzosa et al., 2015; Prosser, 2015; Beale et al., 2016; Manzoni et al., 2016). Several bioinformatic tools have been developed that enable the prediction and identification of secondary metabolites from environmental samples, such as Natural Product Domain Seeker (NaPDoS) (Ziemert et al., 2012), antibiotics and Secondary Metabolite Analysis Shell (antiSMASH) (Medema et al., 2011), NRPSpredictor2 (Röttig et al., 2011), and Environmental Surveyor of Natural Product Discovery (eSNaPD). The NaPDoS pipeline searches genomic or metagenomic data for the 
presence of the KS domain for PKSs and the $\mathrm{C}$ domain for NRPS (Ziemert et al., 2012). This program allows for insight into putative antimicrobial production but is limited due to analysis of only one essential domain for PKSs and NRPSs. The antiSMASH pipeline identifies known antimicrobial production loci using profile hidden Markov models and aligns them with regions of the closest relative gene cluster (Medema et al., 2011), while NRPSpredictor2 utilizes support vector machine-based learning to predict domains (Röttig et al., 2011). The eSNaPD platform can be used for discovery of novel natural products or derivatives of known antimicrobial compounds from metagenomic data (Reddy et al., 2014). While these tools are useful in searching for antimicrobial producing genes, it must be considered that data mining approaches are only as effective as the reference databases provided (Scholz et al., 2012; Kim et al., 2013; Hiraoka et al., 2016; Siegwald et al., 2017).

Databases specific to the PKS and NRPS antimicrobial genes are ClusterMine360 (Conway and Boddy, 2012) and antiSMASH (Blin et al., 2016), which include all of the essential domains needed for antimicrobial synthesis. These manually curated databases can be utilized for mining antimicrobial producing genes from publicly-accessible sequencing data, which lends itself to a unique opportunity as well as a massive challenge. To date, there are approximately 200,000 genomes, 40,000 metagenomes, and 5,000 metatranscriptomes from various environments in publicly available databases (e.g., National Center for Biotechnology Informatics). Mining these data for antimicrobial production using available bioinformatics tools may demonstrate the potential for antimicrobial production at genome-resolved or community-level scales. This has been reflected in sharp rise in the number of publications since 1990 that have included antibiotic or antimicrobial as a keyword or in the title (Figure 3).

\section{ANTIMICROBIALS AS A WEAPON OR A TOOL}

Exploration for natural antimicrobial production has extended to a wide variety of habitats including continental soils (Gottlieb, 1976; Williams and Vickers, 1986; Laskaris et al., 2010), caves (Montano and Henderson, 2013; Cheeptham and Saiz-Jimenez, 2015; Maciejewska et al., 2016), mines (Park et al., 2009; Senhorinho et al., 2018), and marine environments (Rosenfeld and ZoBell, 1947; Burkholder et al., 1966; Patin et al., 2016). The marine environment is a burgeoning source of clinically significant natural products, with over 30,000 previously described and more than 1,000 novel compounds discovered each year since 2008 (Blunt et al., 2016; Lindequist, 2016). Marine biodiversity contains an array of secondary metabolites synthesized by marine microfauna and microflora which are driving the focus of scientific research (Figure 3; Leary et al., 2009). Ocean exploration for new natural products has been driven heavily by medicinal need. However, there is a lack of research on the ecological importance of antimicrobial compounds within natural habitats.

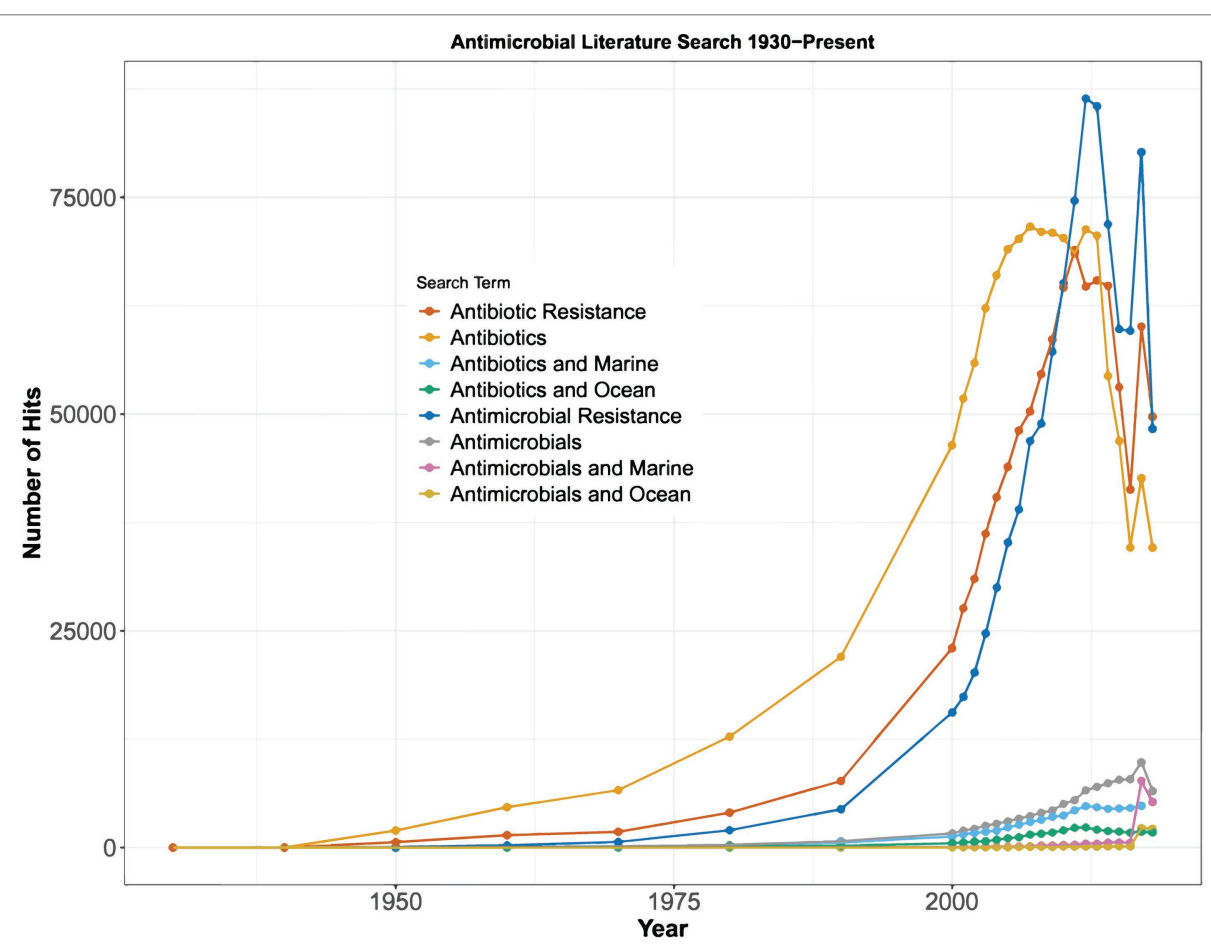

FIGURE 3 | Prevalence of published peer-reviewed literature containing each search term. The earliest study to use the term "antibiotic" was published in 1930. From 1930 to 2000, "hits" were recorded in 10-year increments, and from 2000 to 2018, the number of "hits" was recorded for each year. 
The ecology of microorganisms is complex, due to the number of individuals and vast diversity of natural communities. Fierce competition is driven by a variety of factors such as finite nutrient availability, access to sunlight, and a lack of space. There are two mechanisms of competition. The first is a passive approach, which is resource consumption thus causing indirect competition (Hibbing et al., 2010; Morris, 2015; Ghoul and Mitri, 2016). The second method is through direct interference where microorganisms attempt to "fight" one another through use of chemicals or toxins (Hibbing et al., 2010; Ghoul and Mitri, 2016). Antimicrobial production is the most wellknown example of direct competition. Natural products produced by microorganisms are weaponized to gain a competitive advantage for essential nutrients and space (Chao and Levin, 1981; Riley and Gordon, 1999; Abrudan et al., 2015; Cornforth and Foster, 2015).

Antimicrobials can be divided into many chemical classes and can have a range of actions against neighboring cells. Antimicrobials can be broken down into two large groups: $\beta$-lactams and non- $\beta$-lactams (Donowitz and Mandell, 1988; Clairoux et al., 1992). Within $\beta$-lactams the major classes are penicillins, $\beta$-lactams, cephems, and penems (Clinical and Institute, 2009). The major classes within non- $\beta$-lactams include aminoglycosides, glycopeptides, lipopeptides, macrolides, quinolones, and tetracyclines (Clinical and Institute, 2009). These classes all have various mechanisms of action which include inhibition of cell wall synthesis, protein synthesis, DNA replication and repair, and disruption of the cell membrane (Epand and Vogel, 1999; Lewis, 2013). Antimicrobials also have a range of toxicity which affects the minimum inhibitory concentration (MIC) (Vogelman and Craig, 1986). The MIC is defined as the minimum concentration of an antimicrobial to inhibit growth (Vogelman and Craig, 1986; Li et al., 2017). Antimicrobial MICs can vary between classes and can be affected by surrounding cell concentration and cell type such as resistant, persistent, dormant, biofilm-associated or planktonic microorganisms ( $\mathrm{Li}$ et al., 2017). Based on the respective environment, antimicrobial toxicity can vary. Secondary metabolites including antimicrobials may serve additional roles in communication and cooperation between and among species.

Antimicrobials may also be utilized as a means of communication, i.e. quorum sensing, or enabling commensal or mutualistic relationships within microbial communities (Ghoul and Mitri, 2016). Low doses of potentially harmful environmental stimuli such as of antimicrobials may produce beneficial effects in microbial cells via a process termed hormesis (Southam, 1943; Kendig et al., 2010). The concept of hormesis is not new (Stebbing, 1982); however, antimicrobialinduced hormesis has become a new avenue of research (Yim et al., 2007; Mathieu et al., 2016; Okada and Seyedsayamdost, 2017). Different concentrations of antimicrobial compounds may result in various ecologically significant hormetic effects (Stebbing, 1982; Calabrese, 2005; Davies et al., 2006) influencing the expression of genes potentially involved in elevated virulence in pathogenic Bacteria (Davies, 2006; Linares et al., 2006;
Mathieu et al., 2016; Arseneault and Filion, 2017; Dersch et al., 2017) increased biofilm formation (Hoffman et al., 2005; Ranieri et al., 2018) and mutation frequency (Gillespie et al., 2005; Henderson-Begg et al., 2006), stimulation bacterial adhesion (Fitzpatrick et al., 2002), and enhanced gene transfer (Wang et al., 2005). Diverse classes of antimicrobials have been analyzed to determine their effects on bacterial physiology. For instance, beta-lactam antibiotics that inhibit cell wall biosynthesis have been found to increase biofilm formation, while antimicrobials such as fluoroquinolones targeting specific cellular functions like DNA replication may decrease formation (Marti et al., 2017; Ranieri et al., 2018; Yu et al., 2018). Likewise, some antimicrobials can alter bacterial cell surface properties such as ionic charge and cause more favorable conditions for adherence and biofilm formation (Kumar and Ting, 2013; Kumar and Anthony, 2016; Ranieri et al., 2018). The specific roles of antimicrobial compounds in nature are highly debated, which increases the need for further study in natural environments (Davies, 2006; Keren et al., 2013; Dwyer et al., 2015; Ranieri et al., 2018). The prevalence of antimicrobial-driven symbioses has been demonstrated within terrestrial and marine ecosystems (Hardin, 1960; Hutchinson, 1961; Fredrickson and Stephanopoulos, 1981; Smith and Waltman, 1995; Fontaine et al., 2003; Prosser et al., 2007; Coyte et al., 2015), yet the majority of such studies were conducted using traditional culture-dependent techniques under controlled laboratory conditions, and therefore not representative of the natural environment.

Antimicrobial production in the environment is a relatively young area of research (Riley and Gordon, 1999; Woon and Fisher, 2016; Van Der Meij et al., 2017), which appears to result in a wide range of ecological effects. An antimicrobial compound can cause surrounding cells to enter dormancy (Gilbert et al., 1990; Song et al., 2019), inhibition of specific cellular functions such as DNA replication and repair (bacteriostatic) (Vogelman and Craig, 1986; Lewis, 2013), death (bactericidal) (Nastro and Finegold, 1972; Vogelman and Craig, 1986; Peterson and Shanholtzer, 1992; Voo et al., 2016), become tolerant to the secondary metabolite (Lewis, 2017), or become resistant to the antimicrobial (Cohen, 1992; Riley and Gordon, 1999; Woon and Fisher, 2016). Cells that detect a molecule that is not favorable can go into dormancy until more favorable conditions return (Song et al., 2019). Some dormant cells could become persister cells which are highly tolerant to antimicrobial compounds (Lewis, 2007, 2008, 2010). Cells that become tolerant or resistant to antimicrobials will be able to withstand the metabolites and even proliferate while other populations are inhibited (Lewis, 2010, 2017). It is plausible that all of these events could be occurring simultaneously, which could culminate in shifts in microbial diversity thereby altering the prevailing metabolic function of the environment (Woon and Fisher, 2016). The key to understanding such a theory would be to monitor the environment over time and document shifts as a result of antimicrobial production. As such, there is a lack of natural ecological data in regard to what drives different, uncultured, and/or under-studied 
microbial taxa to produce antimicrobials (Hibbing et al., 2010; Zhu et al., 2014; Van Der Meij et al., 2017).

\section{ARCHAEAL ANTIMICROBIALS}

Antimicrobial production in Bacteria has been studied for over 85 years and Eukarya have been studied for almost 60 years, but Archaea have received comparatively little attention (O'connor and Shand, 2002; Shand and Leyva, 2007). Proteinaceous archaeal antimicrobial compounds (i.e., archaeocins) were discovered in halophiles in 1982 (O'connor and Shand, 2002), and were once thought to be limited to extreme halophiles (i.e., halocins) until sulfolobicin was described in Sulfolobus islandicus, a hyperthermophilic Crenarchaeote found from solfataric fields in Iceland (Prangishvili et al., 2000; O'connor and Shand, 2002). Halocin production has been described as universal across rod-shaped archaeal halophiles, but only a small portion have been characterized (Shand and Leyva, 2007; Mandal et al., 2014). There have been six categories proposed (Rodriguez-Valera et al., 1982), but the type of halocin produced is dependent on the producing microorganism, the surrounding environmental conditions, and growth phase of the culture (Besse et al., 2015). Halocins cause membrane deformation and inhibits $\mathrm{Na}^{+} / \mathrm{H}^{+}$ antiporter in halobacteria (Demain et al., 2019). Sulfolobicins have been found to belong to only members of Sulfobales and affects membrane structure (Demain et al., 2019; Kumar and Tiwari, 2019). Both halocins and sulfolobicins have different structures than bacterial antimicrobials that affect Archaea, which could be indicative of unique compounds yet to be surveyed for medicinal purposes (Nagrale and Gawande, 2018).

Polymorphic toxin systems (PTSs) are used by Bacteria against similar strains or species by cleaving the toxin domain off of the protein upon entry into the neighboring cells (Zhang et al., 2012a; Jamet and Nassif, 2015). The toxins released from the PTSs can attack a wide array of targets including nucleic acids, lipids, and proteins (Zhang et al., 2012a; Makarova et al., 2019). Archaeal homologs of PTSs have been identified but have not been fully explored (Makarova et al., 2019). Makarova et al. surveyed archaean genomes and found 141 genomes to contain genes predicted to encode PTSs (Makarova et al., 2019). Many of the archaeal genomes did not have recognizable self-defense mechanisms compared to bacterial defenses, which can suggest novel or unique self-defense mechanisms that could be creating toxic compounds with antimicrobial activity (Makarova et al., 2019).

The number of cultured Archaea is few compared to Bacteria and fungi; therefore, bioprospecting for antimicrobially active natural products is currently limited in laboratory settings (Gagen et al., 2013; Besse et al., 2015). There has been very little focus on secondary metabolites with potential antimicrobial activity within Archaea (Kumar and Tiwari, 2019; Makarova et al., 2019). Archaea likely contain an array of novel or unique antimicrobial biosynthesis pathways (Roller and Gowan, 2016) that may be elucidated through culture-independent methods, especially considering the widespread distribution of this domain in non-extreme terrestrial and marine environments (Stein and Simon, 1996; Karner et al., 2001; Francis et al., 2005; Biddle et al., 2006; Leininger et al., 2006; Lipp et al., 2008; Zhang et al., 2012b; Seitz et al., 2016; Hoshino and Inagaki, 2019).

\section{CONTINENTAL SOILS, A FERTILE GROUND FOR ANTIMICROBIAL DISCOVERY}

Continental environments are diverse, but only comprise approximately $30 \%$ of Earth's surface. Soils are dynamic due to their heterogenous nature and microbes there are diverse (Raaijmakers and Mazzola, 2012). Soils experience spatial and temporal variation from both abiotic and biotic factors, which can cause microbes to experience difficulty in proliferating and surviving (Raaijmakers and Mazzola, 2012). Nutrient limitation, e.g., nitrogen and phosphorus, as well as increased cellular abundance have been found to induce microbial competition mechanisms including antimicrobial production (Bibb, 2005; Ghoul and Mitri, 2016; Dundore-Arias et al., 2019). Natural product production has been extensively studied in soils since the discovery of penicillin in 1929 (Ligon, 2004).

Although antimicrobials are phylogenetically widespread throughout Bacteria and portions of Archaea and Eukarya, most studies in continental soils have focused on a relatively small fraction of microorganisms that are genetically predisposed to producing antimicrobial compounds (Fiedler et al., 2005; Tiwari and Gupta, 2012). Some of the most notable lineages include Actinomycetales (i.e. actinomycetes), Myxobacteria, Bacillus and, to a lesser extent, some archaeal lineages, filamentous fungi, and Cyanobacteria. The gram-negative Actinobacteria, especially Streptomycetes spp. and spore-forming actinomycetes, produce bioactive compounds demonstrating antibacterial, antifungal, and antitumor activities (Berdy, 1995; Lazzarini et al., 2000). More than 10,000 known bioactive products have been discovered in Streptomyces (Bérdy, 2012; Weber et al., 2015), while some actinomycetes are capable of creating 30-50 secondary metabolites (Katz and Baltz, 2016). Genomic analyses from different ecosystems, such as soils and sediments, have found that between 5 and 10\% of actinomycete genes are for secondary metabolite synthesis, including antimicrobial compounds (Nett et al., 2009; Ghoul and Mitri, 2016).

Although there has been considerable focus on actinomycetes and Streptomycetes, the capacities of these well-studied genera have yet to be exhausted as new genes are currently being discovered from these organisms. For example, new products with antimicrobial activity such as thiopeptide antibiotics have been isolated from Streptomyces (Blunt, 2009; Nandhini et al., 2018; Schneider et al., 2018). Cryptic gene clusters, or biosynthetic clusters that have yet to be identified, have recently been described in this genus via culture-independent data mining through genomics (Aigle et al., 2014; Antoraz et al., 2015; Weber et al., 2015). Thus, both novel and known actinomycetes likely produce uncharacterized secondary metabolites. Myxobacteria have also 
been shown to contain novel antimicrobial producing gene clusters but are typically difficult to culture (Strohl, 2004). Bacillus spp., (a member of Firmicutes phyla) is a prolific producer of cyclic peptides and polyketides that have limited overall structural diversity (Tillett et al., 2000; Stein, 2005). Shifting research to these underexplored groups such as Firmicutes can hold more potential for novel or unique antimicrobial production.

There is some debate regarding the further exploration of continental environments for bioactive molecules. Most literature supports prospecting in unexplored and underexplored ecosystems (Indraningrat et al., 2016; Danilovich et al., 2018), while some still support exploring soil for novel bioactive molecules (Daniel, 2004; Borsetto and Wellington, 2017). One explanation for this debate is the complexity of soils, as they contain distinct microhabitats of differing physicochemical gradients and environmental conditions (Torsvik and Øvreås, 2002) that host diverse microorganisms whose specific metabolisms and interactions are integral to biogeochemical cycling (Daniel, 2004). Additionally, continental soils have the largest microbial abundance per gram in comparison to other ecosystems (Killham, 1994), and complex communities with closely co-located populations may support novel members with the potential to produce secondary metabolites (Crits-Christoph et al., 2018). While these interconnected systems and the secondary metabolites sourced from them have been studied for decades, the limitations of culture-based techniques has led to a drastic decrease in the discovery rate of novel secondary metabolites since the Golden Age (Strohl, 2000; Daniel, 2004). This leaves the remaining question: what are we missing? Culture-independent sequencing methods have pointed us in the right direction of potentially undiscovered natural products or unknown derivatives of known bioactive molecules in alternative environments such as freshwater, marine, and deep subsurface systems.

\section{FRESHWATER EXPLORATION}

Antimicrobial production exploration has extended to freshwater environments over the past few decades (Sibanda et al., 2010; Bharathi et al., 2011; Saravanan et al., 2015; Passari et al., 2017). Much of the research surrounding freshwater antimicrobials has focused on Cyanobacteria due to their contributions to carbon cycling (Stanier and Bazine, 1977; Carmichael, 1994; Herrero et al., 2001; Rai, 2018) and production of toxins that act as direct competition mechanisms (Swain et al., 2017). Cyanobacteria genomes have been shown to contain many gene clusters of PKSs and NRPSs (Christiansen et al., 2001; Schembri et al., 2001; Moffitt and Neilan, 2003; Ehrenreich et al., 2005; Pancrace et al., 2017; Zhang et al., 2017; Demay et al., 2019; Maurya and Mishra, 2019). There have been at least 33 PKS or NRPS clusters experimentally identified within Cyanobacteria and some have been linked to the production of microcystin and anabaenopeptilide in freshwater and marine environments (Pancrace et al., 2017). Microcystins and anabaenopeptilides are secondary metabolites that inhibit protein phosphatases and serine proteases, respectfully (Repka et al., 2004). Both of these toxins can be used to inhibit protein synthesis thus inhibiting surrounding microorganisms from proliferating. Multiple species of Cyanobacteria produce antimicrobials that defend against harmful pathogens such as B. subtilis, S. aureus, Streptococcus mutans, and E. coli (Madhumathi et al., 2011). Microcystis aeruginosa and Nodularia spumigena produce microcystin and nodularin, which are used to inhibit surrounding community members (Moffitt and Neilan, 2000, 2001; Tillett et al., 2000). However, analyses of the ketosynthase domain within PKS genes have revealed more biosynthetic diversity within Cyanobacteria genera including Cylindrospermopsis and Umezakia (Moffitt and Neilan, 2003). Freshwater Cyanobacteria encode diverse PKSs and NRPSs are and able to produce a wide array of antimicrobial compounds including cyclic peptides, macrolides, and terpenoids (Ehrenreich et al., 2005; Busti et al., 2006; Frangeul et al., 2008; Silva-Stenico et al., 2011; Swain et al., 2017). These studies suggest that Cyanobacteria may contain uncharacterized biosynthetic gene clusters or create novel compounds. Additionally, it has been suggested that undifferentiated filamentous and heterocystous strains (e.g., Anabaena, Nodularia, Nostoc, and Spriulina) show the greatest potential for natural product biosynthesis (Ehrenreich et al., 2005). Over 60\% of Cyanobacteria genera are capable of biosynthesizing secondary metabolites with putative antimicrobial activity (Demay et al., 2019). There have been 260 compound families of Cyanobacteria secondary metabolite products and can have a range of activities including lethality, cytotoxicity, antibacterial, anti-microalgal, and enzyme inhibition (Demay et al., 2019). Due to their PKS and NRPS diversity (Brito et al., 2015; Mazard et al., 2016), Cyanobacteria will likely be the primary focus for future exploration of novel or unique antimicrobials in freshwater environments. Putative antimicrobial activity is suspected based on the discovered gene clusters; however, many of the gene clusters have only been observed from a culture-independent standpoint (Demay et al., 2019). Cyanobacteria also have been heavily investigated for the toxin production that can have an antimicrobial affect (Carmichael, 1992, 1994; D'agostino et al., 2016). Detection of PKS and NRPS domains is an important first step in identifying putative antimicrobial production. To definitively state that antimicrobial production is occurring, both culture-dependent and culture-independent needs to be performed. Determining the ecology of Cyanobacteria secondary metabolite producers would require culture-dependent methods to have concrete evidence of antimicrobial activity (Demay et al., 2019).

Many Bacteria isolated from freshwater environments have shown antimicrobial activity including Actinobacteria and Proteobacteria which are typically highly abundant phyla in freshwater sediment communities (Zhang et al., 2015; Zothanpuia et al., 2016; Chung et al., 2018; Nam et al., 2018; Passari et al., 2018; Koch et al., 2019). Isolates collected from sediments in Tamdil Lake, India belonged to 10 different genera and seven of the isolates had type II PKS and NRPS (Zothanpuia et al., 2016; Passari et al., 2018). Detection of these genes was performed using PCR selecting for the ketosynthase domains and adenylation domains for PKS and NRPS, respectively (Zothanpuia et al., 2016). Along with the detection of PKS and NRPS domains, the isolates were grown and tested for antimicrobial production by analyzing the zones of clearing, also known as zones of 
inhibition, around the inoculation site (Zothanpuia et al., 2016). The isolates containing biosynthetic gene domains were identified as Staphylococcus, Methylobacterium, Lysinibacillus, Bosea, Aneurinibacillus, Bacillus, and Novosphingobium (Zothanpuia et al., 2016). Detection of biosynthetic gene clusters in these isolates is the first step in determining the ecology of PKS and NRPS metabolites in situ. Determining what metabolite is created, the mechanism of action can be determined which can then elucidate what that metabolite is being used for against surrounding community members. All of these genera have been underexplored for antimicrobial production, especially Novosphingobium, which could indicate an untapped reservoir for unique or novel antimicrobial genes (Zothanpuia et al., 2016). An isolate from Nakdong River, South Korea was identified as Paucibacter aquatile and contains nine biosynthetic gene clusters that are involved in lantipeptide, bacteriocin, terpene, and NRPS biosynthesis (Chung et al., 2018). Lantipeptides and terpenes do extensive damage to microbial cell walls thus killing surrounding cells (Chatterjee et al., 2005; Sieniawska et al., 2017). Lantipeptides and terpenes could be used to lyse surrounding cells to gain access to nutrients harbored by the surrounding cells, eliminate competition, or gain access to spatial resources (Chatterjee et al., 2005; Sieniawska et al., 2017). Bacteriocins are much more diverse in mechanisms of action so these ribosomal produced molecules could inhibit or kill surrounding cells (Yang et al., 2014). Bacteriocins could be used as a competitive advantage to eliminate different types of surrounding microbial cells based on the mechanism of action (Yang et al., 2014). To date, there are only three cultured representatives within Paucibacter, which could be a prolific antimicrobial producer based on preliminary screenings and genome analyses (Pheng et al., 2017; Chung et al., 2018; Nam et al., 2018).

\section{MINING FOR ANTIMICROBIALS}

Terrestrial mines have been heavily investigated for microbial communities adapted for the extreme conditions, such as $\mathrm{pH}$, temperature, lack of sunlight, and nutrient limitation, associated with mining activity (Rowe et al., 2007) and acid mine drainage (Baker and Banfield, 2003). Many factors can affect antimicrobial production including oxygen, temperature, $\mathrm{pH}$, carbon, nitrogen, and phosphorus availability (Raaijmakers et al., 2002). Fermentation is the dominant metabolism that creates antimicrobial products (Harms et al., 2017). If there is high oxygen concentration, then fermentation will not occur, thus causing inhibition of antimicrobial production. Microorganisms have optimum temperature and $\mathrm{pH}$ for growth and for metabolic activity (Nastro et al., 2011; Wang et al., 2011; Vijayakumari et al., 2013). Temperature can affect the microorganism's ability to proliferate and metabolize efficiently (Gillooly et al., 2001). The enzymes produced from metabolic activity including products of PKSs and NRPSs can have reduced affinity for its respective substrates if the $\mathrm{pH}$ is too far from the microbe's optimum, which can then cause enzymes to be less efficient (Dixon, 1953). Antimicrobial production can be upregulated in environments with limited phosphate and nitrate availability (Bibb, 2005; Van
Wezel and Mcdowall, 2011; Liu et al., 2013; Van Der Heul et al., 2018). Some mines have been characterized to be nutrient limited especially in phosphate such as Sanford Underground Research Facility (Osburn et al., 2014). Mining also produces acid mine drainage which causes a large amount of metals and sulfides to be introduced to the environment (Baker and Banfield, 2003). Metal precipitates in acid mine drainage has been found to have an indirect effect on nutrient availability including phosphorus (Hogsden and Harding, 2011; Denicola and Lellock, 2015). Further examination of mines including the abiotic factors could give insight into regulation of antimicrobial production.

A study conducted on an abandoned coal mine in South Korea found eight antimicrobial compounds from a Streptomycete isolate exhibited moderate activity against $M$. luteus, E. hirae, and methicillin resistant Staphylococcus aureus (MRSA) (Park et al., 2014). Alkaline mines have also been found to host microorganisms capable of antimicrobial production (Hill et al., 2017). A Nocardiopsis sp. isolated from alkaline mine waste from China produced Napthospironone A, which exhibited moderate activity against B. subitilis, E. coli, S. aureus, and Aspergillus niger (Ding et al., 2010). This finding suggests that mine-sourced antimicrobials may be used to combat emerging resistant strains of Bacteria such as S. aureus and E. coli. Further determination of what secondary metabolites are produced from these isolates would give tremendous insight into how the antimicrobial(s) affect the ecology of the surrounding environment. For example if the antimicrobial compounds are determined to inhibit surrounding microbial cells, then we could hypothesize that the antimicrobial producer is trying to gain access to surrounding nutrients or spatial resources. If the antimicrobials lyse surrounding cells, then we could hypothesize a predatory interaction where the producer is using the lysed cell for energy rather than what is available in the surrounding environment.

Many mines are rich in heavy metals including copper, iron, nickel, cadmium, and chromium, which have been found to increase or decrease secondary metabolism in many prokaryotes and fungi (Chakrabarty and Roy, 1964; Weinberg, 1990; Haferburg et al., 2007). Streptomyces galbus can produce antifungals when their medium includes copper, zinc, or iron, but can experience reduction of antimicrobial production in the presence of cadmium (Paul and Banerjee, 1983; Raytapadar et al., 1995; Haferburg et al., 2007). Chromium has been used to increase actinorhodin production from Streptomyces coelicolor (Abbas and Edwards, 1990; Haferburg et al., 2007). Antimicrobial compounds that are found in the presence of metals can form strong complexes such as chloramphenicol in the presence of calcium, iron, palladium, and gold, which can further enhance their activity against surrounding microorganisms such as $S$. aureus, E. coli, B. subtilis, and P. aeruginosa (Al-Khodir and Refat, 2016). Such complex interactions between microorganisms and the surrounding geochemistry could drive the production of novel compounds not seen in model laboratory systems (Jose and Jebakumar, 2014; Hill et al., 2017). Antimicrobial gene regulation has been studied in the model genus Streptomyces and found in nutrient limitation such as nitrate; antimicrobial production is increased (Chakraburtty and Bibb, 1997; Song et al., 2004; Bibb, 2005). Many environments like mines are 
oligotrophic and are limited in nitrate, which could therefore induce antimicrobial production. This hypothesis of oligotrophy driving antimicrobial production can be used to target specific environments for putative natural antimicrobial production.

\section{CAVING FOR UNKNOWN ANTIMICROBIALS}

It is estimated that only $10 \%$ of all caves have been discovered and only half of the known caves have been explored (Ghosh et al., 2017). Caves contain isolated environments within Earth's subsurface that are devoid of sunlight, making them an extreme environment for life (Northup and Diana, 2001). Low nutrients can encourage competition for limited resources which can lead to antimicrobial production to inhibit or eliminate surrounding microorganisms (Kuenen and Bos, 1989; Summers Engel et al., 2001; Fontaine et al., 2003; Zeppilli et al., 2018).

The production of novel antimicrobial compounds has been investigated in continental and marine caves over the past 30 years (Ghosh et al., 2017). Analysis of microbial community structure from various caves has revealed new species of actinomycetes (Groth et al., 1999; Lee et al., 2000; Jurado et al., 2005), which may be promising leads to new antimicrobial products (Ningthoujam et al., 2009; Cheeptham and Saiz-Jimenez, 2015). For example, cave soils from Phatup Cave Forest Park and Phanangkhoi Cave in Thailand yielded four actinomycete-sourced natural product isolates that exhibited inhibition of virulent Bacteria and tumor cells including Bacillus cereus, MRSA, and breast cancer (Nakaew et al., 2009). Over 400 actinomycetes isolates from soils and rocks located in Helmcken Falls Cave in British Columbia were screened for antimicrobial activity against Candida albicans, Micrococcus luteus, Mycobacterium smegmatis, Psuedomonas aeruginosa, Acinetobacter baumannii, Klebsiella pnuemoniae, and extended spectrum $\beta$-lactamase Escherichia coli (Cheeptham, 2013). Many Bacteria have become resistant to existing antimicrobials via interaction with surrounding secondary metabolites naturally created and from medicinal purposes thus increasing the need for novel or unique compounds to combat them (Nakaew et al., 2009; Yücel and Yamaç, 2010; Rajput et al., 2012; Cheeptham, 2013; Montano and Henderson, 2013). Future analyses should focus on what types of antimicrobials are produced in order to determine the target for of the secondary metabolites, e.g., cell wall synthesis inhibition or protein synthesis inhibition. Upon discovery of the target, we may be able to determine what is happening in situ between the producer and the target.

Streptomyces and Nocardia isolates from Siberian carbonate cave deposits produced antimicrobial and antifungal compounds (Axenov-Gibanov et al., 2016). These Streptomyces are one of the most prolific producers of antimicrobial compounds, and finding isolates that produce antimicrobial compounds within oligotrophic systems further supports the hypothesis of nutrient limitation driving natural product biosynthesis (Maciejewska et al., 2017). Samples from Mystery Cave and Norman's Cave in Exuma Cays, Bahamas were shown to contain four genera with genes specific for PKS and/or NRPS pathways (Hodges et al., 2012). Submarine caves pose a unique extreme environment for microbial communities including salinity gradients (Fichez, 1990; Sket, 1996), limited nutrients (Ghosh et al., 2017), and anoxic conditions (Jaume and Boxshall, 2009). Thus far few studies have been conducted on microbial ecology in submarine caves that focus on antimicrobial production. Cave exploration for antimicrobial production can lead to more insight into microbial ecology in extreme environments and possibly novel or unique compounds (Zeppilli et al., 2018).

\section{DIVING INTO THE ABYSS FOR ANTIMICROBIAL DISCOVERY}

The diversity of oceanic habitats is extensive, ranging from shallow, sunlit neritic zones to the eternal darkness of the hadalpelagic, from eutrophic coastal environments to oligotrophic gyres. Exploiting various environments for antimicrobial compounds have diversified in the past decades to include marine ecosystems (Figure 3), yet many of these have yet to be explored for unique antimicrobial products. Bioinformatic data mining has been used to analyze existing metagenomic datasets to identify putative essential PKS and NRPS domains such as those from the 20062007 Galathea 3 global multidisciplinary research expedition (Machado et al., 2015; Marchado, 2016; Kealey et al., 2017). Within this data mining venture, a total of 21 genomes belonging to Alphaproteobacteria and Gammaproteobacteria were found to contain numerous clusters with potential antimicrobial activity (Machado et al., 2015). Another study that included metagenomic sequencing from the Rabigh coast of Saudi Arabia recovered many taxa (e.g., Proteobacteria, Bacteroides, Actinobacteria, Cyanobacteria, Acidobacteria, and Firmicutes) that contained antibiotic portions of PKS and NRPS gene domains (Al-Amoudi et al., 2016). This study found taxa that are not traditionally targeted for antimicrobial production, like actinomycetes.

Actinomycetales have received extensive research in oceanic environments (Zhu et al., 2014; Weber et al., 2015). Actinomycetes can survive a wide range of environmental conditions such as high pressure (maximum of 1,100 atm) (Colquhoun et al., 1998a,b; Kim et al., 2006), temperatures $\left(0-100^{\circ} \mathrm{C}\right)$ (Fergus, 1964; Cross, 1968; Whyte et al., 1999; Kim et al., 2006), oxic or anoxic conditions (Goodfellow and Williams, 1983), and pH (2.8-10.5) (Williams et al., 1971; Schippers et al., 2002; Kim et al., 2006; Mehta et al., 2006). The ubiquity of actinomycetes has led to increasing efforts in their recovery and isolation from marine environments for bioprospecting potential antimicrobial compounds. Imada et al. (2007) showed that the removal of seawater from culture media ceased antimicrobial production in marine actinomycetes. This finding supports the idea of certain conditions within a marine ecosystem upregulate the expression of antimicrobial production genes.

The marine environment is highly diverse and contains many dynamic habitats that contain specialized microbial communities. All environmental parameters must be considered when interpreting microorganisms' function within a specific environment. The nutrients that are available for use can dictate which microbes are present and actively functioning. Physical parameters can affect the biogeography of microorganisms. The marine environment hosts many dynamic systems, which can host diverse microbial 
communities. A comprehensive approach of analysis including biotic and abiotic data will give more clarity to what is driving microorganisms to produce antimicrobial compounds.

\section{DRILLING DOWN TO DISCOVER ANTIMICROBIALS IN THE DEEP SUBSURFACE}

The deep subsurface biosphere was generally defined as life present greater than $1 \mathrm{~m}$ below seafloor (mbsf) (Jørgensen and Boetius, 2007; Orsi et al., 2013b), but has been updated to establish an age and depositional setting (Kirkpatrick et al., 2016). Subsurface microbial life is widespread, with communities documented in oceanic crust and sediments as deep as 2,458 mbsf (Inagaki et al., 2015). The deep subsurface is considered an extreme environment due to low and high temperatures, high pressure, lack of nutrient/carbon availability, and represents an ideal location to understand how microbial populations co-exist under resource-limited conditions. As depth increases, metabolism slows and growth rate decreases, suggesting that cell maintenance may be the most important factor for survival (Jørgensen and Marshall, 2016). How microbial communities survive (and possibly thrive) within this environment is an ongoing question that has continued to drive research there. To date, research in these environments has predominantly focused on prokaryote metabolism and biogeochemical cycling (Orcutt et al., 2013; Orsi et al., 2013b; Baker et al., 2015; Long et al., 2016; Zinke et al., 2017; Orsi, 2018; Reese et al., 2018). However, no studies to date have focused on the prevalence of antimicrobial production or antimicrobial resistance in the deep subsurface biosphere.

Some studies have identified the potential for antimicrobial production via metatranscriptomics (Orsi et al., 2013b; Zinke et al., 2017) as well as culture-dependent techniques (PathomAree et al., 2006). In the latter study, actinomycetes were found from the Mariana Trench and identified using species-specific primers targeting this specific taxon of microorganisms. Of the 38 samples, over half had NRPS gene sequences and nine had PKS Type I gene sequences (Pathom-Aree et al., 2006). Some of the recovered gene sequences encoding for putative secondary metabolite production could not be identified when compared to existing databases. The presence of potentially novel NRPS and PKS genes warrants further research to determine which secondary metabolites are likely produced in the deep subsurface.

Deeply buried sediments from the Peru Margin (Ocean Drilling Program Leg 201, Site 1229D) were used for metatranscriptome analyses to examine putatively active microorganisms functioning within the sediment. This study concluded that Actinobacteria were one of the dominant metabolically active groups, as they were represented in every mRNA sample from site 1229D (Orsi et al., 2013a). Secondary metabolite biosynthesis was also found in every depth sampled; however, Actinobacteria were not the only taxa producing these PKSs and NRPSs (Orsi et al., 2013b). Other notable taxa producing PKSs and NRPSs include Bacteroidetes, Firmicutes, and Proteobacteria (Orsi et al., 2013b). Actinobacteria with
PKSs and NRPSs were dominant in shallower samples, but decreased in abundance with increasing depth. The deeper sediment samples contained mostly Betaproteobacteria and Gammaproteobacteria with PKSs and NRPSs. This finding indicates that there are other taxa producing compounds that could be novel or unique.

Assuming Actinobacteria to be the most prolific producers of antimicrobials, the discovery and isolation of novel members of these lineages provide promise for antimicrobial activity in other subsurface environments (Thornburg et al., 2010). Actinomycete species have been found from deep-sea environments including hydrothermal vent fluids within the Mariana Trough and Suiyo Seamount (Kysela et al., 2005) and hydrothermal sediments of Guaymas Basin (Naganuma et al., 2007). Many deep subsurface environments have been explored through 'omics' to analyze microbial community structure and function, but in doing so have also stumbled upon a hotbed of actinomycete lineages. Bacterial 16S rRNA gene sequences related to actinomycetes have been found in deep ocean water column and sediment (Cole et al., 2007, 2008; Huber et al., 2007; Thornburg et al., 2010). In the course of this review, we used assembled metagenomic data collected from IODP Expedition 327 to Juan de Fuca Ridge basaltic fluids (Jungbluth et al., 2017), the IODP Expedition 336 to the western Flank of the Mid-Atlantic Ridge basaltic fluids (Meyer et al., 2016), South Africa Gold Mine (Lau et al., 2014; Magnabosco et al., 2014), and the Coast Range Ophiolite Microbial Observatory (Twing et al., 2017) and analyzed for putative antimicrobial production using the NaPDoS pipeline (Ziemert et al., 2012). The western Flank of the Mid-Atlantic Ridge is commonly referred to North Pond due to the large pond of sediment located on the western side of the ridge above basalts (Langseth et al., 1992). The condensation domain of the NRPS gene was found in all deep subsurface data analyzed through NaPDoS (Figure 4), illustrating the diversity of antimicrobial-related sequences within deeply buried marine environments. In contrast, the ketosynthase domain of the PKS gene was found in all subsurface sites for fatty acid synthesis (Figure 5). Only samples collected from North Pond basaltic fluids contained ketosynthase-related sequences associated with antimicrobial production. Fatty acid synthesis and antibiotic production genes are very similar to one another, and antimicrobial PKSs may be derived from fatty acid synthesis genes (Hopwood, 1999; Metz et al., 2001; Tsai, 2018). The similarity between antimicrobial PKSs and fatty acid synthesis genes may explain why there are two distinct clades (Figure 5). Many marine Bacteria have expressed fatty acid synthesis genes with homology to PKS genes (Metz et al., 2001), particularly within subsurface environments. Sedimentary (and basalt-hosted) microorganisms could be utilizing the PKS gene to synthesize fatty acids necessary for cellular structures like the cell membrane (Metz et al., 2001; Selvin et al., 2016; Tsai, 2018). The deeply buried marine biosphere may host novel or unique antimicrobial activity that contributes to the intricate ecology of the system, microbe-microbe interactions, and habitability.

Here, we illustrate the usefulness in metagenomic studies to elucidate putative antimicrobial production as well as the caveats of such an approach. The possibility of capturing antimicrobial 




FIGURE 4 | Phylogenetic tree of the condensation domain of the NRPS gene including sequences from terrestrial deep subsurface and marine deep subsurface sites. The reference sequences are from the Natural Product Domain Seeker (NaPDoS) repository. The alignment and tree were built using the NaPDoS pipeline (Ziemert et al., 2012). Red dots indicate bootstrap values greater than 50\%.

producing genes from solely culture-independent studies can save time and resources (Handelsman et al., 1998; Banik and Brady, 2010; Garcia et al., 2018). Metagenomic analyses are valuable in that researchers can identify putative metabolic processes including antimicrobial production (Bergmann et al., 2007). Although, DNA-based analyses is an excellent first step at identifying potential microbial activities, metagenomic analyses can also detect dormant, dead, or low metabolically active community members (Davis et al., 1986; Orcutt et al., 2013). Taken as a hypothesis-driving guide, metagenomics can uncover hidden potential for antimicrobials, but ideally metatranscriptomics, proteomics, and metabolomics should be performed. A combination of approaches to analyze antimicrobial production would be more efficient and supportive. Thus far many studies have only surveyed antimicrobial production via gene-based (Moffitt and Neilan, 2003; Zothanpuia et al., 2016; Demay et al., 2019), culture-dependent (Nakaew et al., 2009; Ding et al., 2010; Cheeptham, 2013; Axenov-Gibanov et al., 2016), and metagenomic studies (Machado et al., 2015; Al-Amoudi et al., 2016; Kealey et al., 2017). Most surveying for antimicrobial production has previously focused on detection of PKS and/or NRPS domains by PCR amplification (Moffitt and Neilan, 2003; Ehrenreich et al., 2005; Pathom-Aree et al., 2006; Hodges et al., 2012; Zothanpuia et al., 2016; Passari et al., 2018). This has been an enlightening approach to survey for putative antimicrobial production. However, this process only identifies one domain present within a given sample. An 'omics' approach will give the opportunity to find longer portions and possibly the entirety of PKS and NRPS genes. Metagenomics has become a more prominent source for surveying natural environments but is limited in determining activity. Metatranscriptomics, proteomics, and metabolomics would yield more concrete results of antimicrobial production (Orcutt et al., 2013).

\section{PUTTING ANTIMICROBIALS ON THE MAP}

There is a pressing need for increased exploration of antimicrobials in natural environments due to the lack of information regarding the ecological roles of these compounds. The most favorable locales for bioprospecting can be determined through microbial biogeography, which encompasses spatial distributions, dispersal, and inter- and intraspecies interactions (Martiny et al., 2006) to better understand microbial communities across various environments (Coleman et al., 2006). Analysis of environmental and geochemical parameters including temperature, salinity, $\mathrm{pH}$, depth, nitrogen, carbon, and phosphorus can be used to gain insight to why these microorganisms are producing antimicrobial 


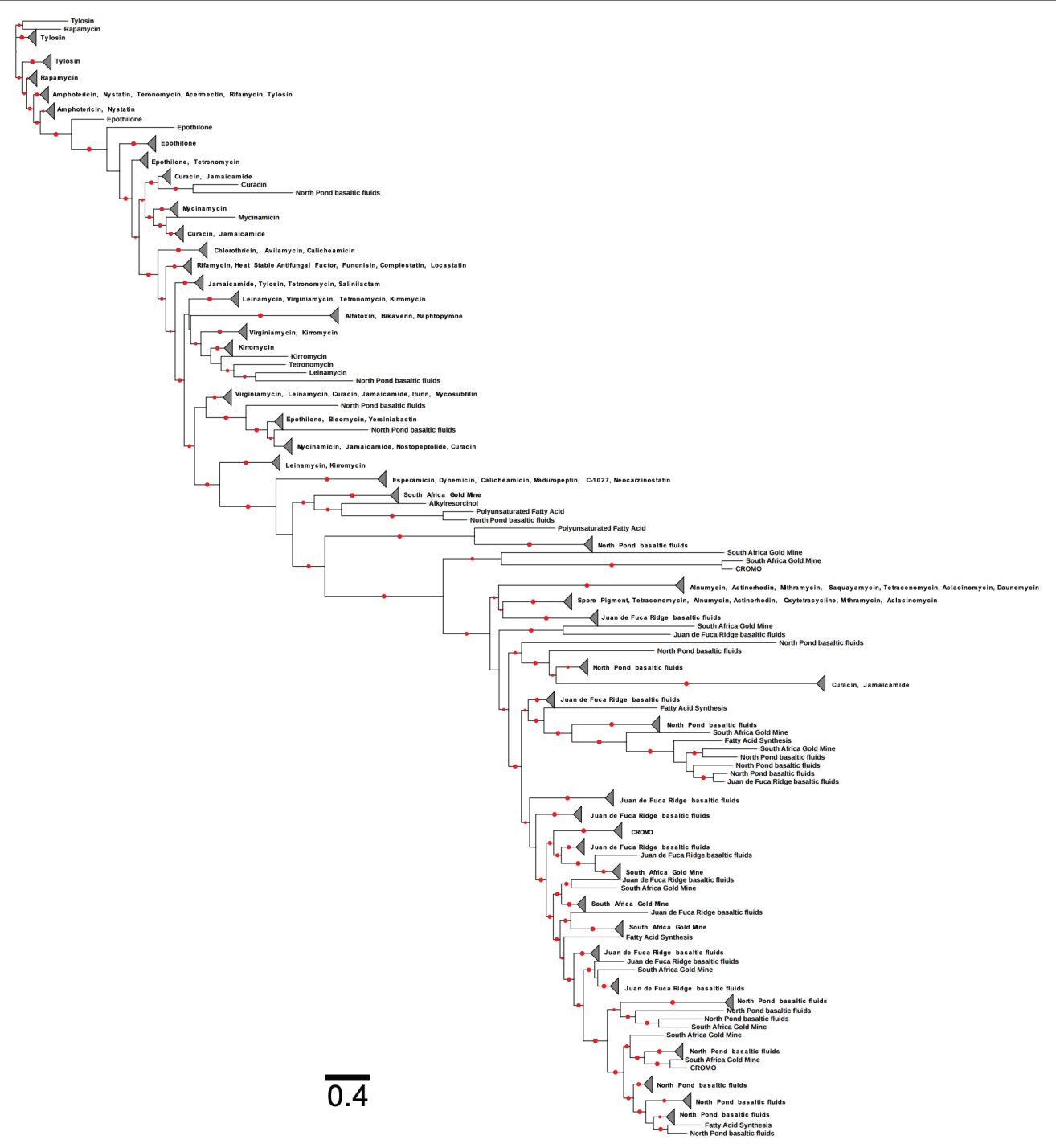

FIGURE 5 | Phylogenetic tree of the ketosynthase domain of the PKS gene including sequences from terrestrial and marine deep subsurface sites. The reference sequences are from the Natural Product Domain Seeker (NaPDoS) repository. The alignment and tree were built using the NaPDoS pipeline (Ziemert et al., 2012). Red dots indicate bootstrap values greater than $50 \%$.

compounds. This data collection strategy can be applied to each environment sampled for biosynthesis exploration. Each environment hosts a unique ecosystem that shapes how microbial communities interact and survive. A biogeographical approach not only incorporates the traditional methods of isolating bioactive compounds from natural environments, but also includes bioinformatic methods that aid in the discovery of uncultured microbes with the genetic potential to produce novel or unique antimicrobials. Assessing spatiotemporal trends in antimicrobial production through biogeography would provide a means to predict the presence and prevalence of antimicrobial compounds in different ecosystems. Yet, the few published studies on the biogeography of antimicrobial production have shown that spatial distributions are directly correlated with sequence differences in antimicrobial genes (Reddy et al., 2014; Morlon, 2015; CharlopPowers et al., 2015). PKS and NRPS genes from environments in close proximity were more similar than those that were globally distant (Charlop-Powers et al., 2015), which is to be expected.

Future antimicrobial-focused biogeography studies may benefit greatly from the vast quantities of publicly-available sequencing data, such as the creation and curation of maps of sample isolation sites within the eSNaPD (Reddy et al., 2014) which represent hot spots for antimicrobial production. While these tools are useful in searching for antimicrobial producing genes, it must be considered that data mining approaches are only good as the databases provided (Medema et al., 2011; Ziemert et al., 2012; Reddy et al., 2014). Creating a hand-curated database containing each essential domain that could be present within the PKS or NRPS gene would be more useful to deduce antimicrobial production potential. Existing databases are a good resource for data mining; however, the results will be heavily dependent on the database. Constructing a comprehensive 
database that includes all variants of genes of interest, such as antimicrobial production, will give the best chance in correctly identifying putative functional genes (Boolchandani et al., 2019). Using one essential domain offers preliminary analysis of presence-absence; however, using multiple domain searches is ideal for supporting antimicrobial production from only cultureindependent data. Using a multi-domain search approach for antimicrobial production will give more concrete evidence of putative antimicrobial production. Based on the domains present and the organization of the domains will be more efficient in determining functionality of the secondary metabolite. A single domain offers support of putative antimicrobial production because causes difficulty in determining the secondary metabolite that it encodes. Constructing a large-scale biogeography that encompasses various environments accompanied with physical and geochemical data can give tremendous insight into future exploration. A streamlined guide to antimicrobial exploration will offer better chances to understand microbial ecology and potentially discover novel compounds.

\section{FUTURE DIRECTIONS}

Generally, the microbial bioactive compounds that have been discovered come from actinomycetes (45\%), fungi (38\%), and unicellular eubacteria (17\%) (Mahajan and Balachandran, 2012), but these numbers do not reflect the potential discoveries that remain if we expand our studies to include underexplored ecosystems and additional domains of life. The studies reviewed here have provided a valuable foundation for antimicrobial exploration and bioprospecting by demonstrating the presence/ absence of the PKS and NRPS genes. However, we know that for secondary metabolite biosynthesis to occur, PKS and NRPS antimicrobial genes necessitate every one of their three essential domains, yet research thus far has solely focused on one domain to indicate antimicrobial production. Future studies from all environments must incorporate all three essential domains to effectively demonstrate putative antimicrobial production or risk mischaracterizing the prospect of biosynthesis. This necessitates the need for more complete databases to include all domains. Additionally, the vast majority of studies have utilized only the PKS or NRPS gene (i.e., DNA) as a proxy for antimicrobial activity, which does not necessarily mean that it is being expressed. Using metatranscriptomics as a proxy for microbial activity and gene expression is a first step in overcoming this issue. Lastly, in order to delve into a more thorough understanding of bioprospecting, we must first establish commonalities among sites with high frequency of antimicrobial genes. In order to do this, a myriad of environments must be explored, and abiotic data must be collected. This will provide a more holistic approach to what drives putative antimicrobial production and will give invaluable insight into microbial ecology in natural environments.

Further exploration of antimicrobial production within microbial communities will not only provide a more comprehensive understanding of their ecology with regards to overarching factors such as biogeochemical cycling but also increase potential natural product discovery. Antimicrobial compounds are utilized by specific microorganisms for competition purposes to obtain vital nutrients and spatial resources for survival. Thus far, our knowledge of antimicrobials has been from studies focused on terrestrial environments. However, the marine deep subsurface, one of the largest habitats on Earth, has yet to be explored for antimicrobial genes and products. Understanding the ecology of microbial communities in harsh, remote environments can aid in determining the limits of life as well as microorganisms' contributions to overall ecology through competition.

\section{AUTHOR CONTRIBUTIONS}

MM and BR developed the idea for the review. MM and IR analyzed data. MM and BR wrote the review. BB contributed ideas and assisted in editing.

\section{ACKNOWLEDGMENTS}

We would like to thank the Science Parties and Crews for IODP Expedition 336 (Mid-Atlantic Ridge Microbiology) and IODP Expedition 327 (Juan de Fuca Ridge Flank Hydrogeology) for installation of Circulation Obviation Retrofit Kits and sample collection. We thank William Brazelton and Katrina Twing for sample collection and sequence generation at Coast Range Ophiolite Microbial Observatory and for making data accessible to the public. We would like to thank Gold Fields Ltd., Harmony Gold Co. Mining Ltd., Petra Diamonds and AngloGold Ashanti Ltd., South Africa and the management and staff of Beatrix, Driefontein, Masimong, Finsch, and Tau Tona mines for access to data. We thank Benjamin Tully for bioinformatic guidance and the helpful comments of the reviewers. We thank the Deep Carbon Observatory's Census of Deep Life for access to data and publication assistance. This is contribution number 496 to the NSF Science and Technology Center for Dark Energy Biosphere Investigations (C-DEBI).

\section{REFERENCES}

Abbas, A. S., and Edwards, C. (1990). Effects of metals on Streptomyces coelicolor growth and actinorhodin production. Appl. Environ. Microbiol. 56, 675-680. Abraham, E. (1962). The cephalosporins. Pharmacol. Rev. 14, 473-500.

Abrudan, M. I., Smakman, F., Grimbergen, A. J., Westhoff, S., Miller, E. L., Van Wezel, G. P., et al. (2015). Socially mediated induction and suppression of antibiosis during bacterial coexistence. Proc. Natl. Acad. Sci. 112, 11054-11059. doi: 10.1073 /pnas. 1504076112

Adu-Oppong, B., Gasparrini, A. J., and Dantas, G. (2017). Genomic and functional techniques to mine the microbiome for novel antimicrobials and antimicrobial resistance genes. Ann. N. Y. Acad. Sci. 1388, 42-58. doi: 10.1111/nyas.13257

Aigle, B., Lautru, S., Spiteller, D., Dickschat, J. S., Challis, G. L., Leblond, P., et al. (2014). Genome mining of Streptomyces ambofaciens. J. Ind. Microbiol. Biotechnol. 41, 251-263. doi: 10.1007/s10295-013-1379-y

Al-Amoudi, S., Razali, R., Essack, M., Amini, M. S., Bougouffa, S., Archer, J. A., et al. (2016). Metagenomics as a preliminary screen for antimicrobial bioprospecting. Gene 594, 248-258. doi: 10.1016/j.gene.2016.09.021 
Al-Khodir, F. A., and Refat, M. S. (2016). Synthesis, spectroscopic, thermal and anticancer studies of metal-antibiotic chelations: Ca (II), Fe (III), Pd (II) and au (III) chloramphenicol complexes. J. Mol. Struct. 1119, 157-166. doi: 10.1016/j.molstruc.2016.04.069

Aminov, R. I. (2009). The role of antibiotics and antibiotic resistance in nature. Environ. Microbiol. 11, 2970-2988. doi: 10.1111/j.1462-2920.2009.01972.x

Andersson, M. I., and Macgowan, A. P. (2003). Development of the quinolones. J. Antimicrob. Chemother. 51, 1-11. doi: 10.1093/jac/dkg212

Ansari, M. Z., Yadav, G., Gokhale, R. S., and Mohanty, D. (2004). NRPS-PKS: a knowledge-based resource for analysis of NRPS/PKS megasynthases. Nucleic Acids Res. 32, W405-W413. doi: 10.1093/nar/gkh359

Antoraz, S., Santamaría, R. I., Díaz, M., Sanz, D., and Rodríguez, H. (2015). Toward a new focus in antibiotic and drug discovery from the Streptomyces arsenal. Front. Microbiol. 6:461. doi: 10.3389/fmicb.2015.00461

Aparicio, J. F., Molnár, I., Schwecke, T., König, A., Haydock, S. F., Khaw, L. E., et al. (1996). Organization of the biosynthetic gene cluster for rapamycin in Streptomyces hygroscopicus: analysis of the enzymatic domains in the modular polyketide synthase. Gene 169, 9-16. doi: 10.1016/0378-1119(95)00800-4

Arseneault, T., and Filion, M. (2017). Biocontrol through antibiosis: exploring the role played by subinhibitory concentrations of antibiotics in soil and their impact on plant pathogens. Can. J. Plant Pathol. 39, 267-274. doi: 10.1080/07060661.2017.1354335

Austin, M. B., and Noel, J. P. (2003). The chalcone synthase superfamily of type III polyketide synthases. Nat. Prod. Rep. 20, 79-110. doi: 10.1039/ b100917f

Axenov-Gibanov, D. V., Voytsekhovskaya, I. V., Tokovenko, B. T., Protasov, E. S., Gamaiunov, S. V., Rebets, Y. V., et al. (2016). Actinobacteria isolated from an underground lake and moonmilk speleothem from the biggest conglomeratic karstic cave in Siberia as sources of novel biologically active compounds. PLoS One 11:e0149216. doi: 10.1371/journal.pone.0149216

Baker, B. J., and Banfield, J. F. (2003). Microbial communities in acid mine drainage. FEMS Microbiol. Ecol. 44, 139-152. doi: 10.1016/ S0168-6496(03)00028-X

Baker, B. J., Lazar, C. S., Teske, A. P., and Dick, G. J. (2015). Genomic resolution of linkages in carbon, nitrogen, and sulfur cycling among widespread estuary sediment bacteria. Microbiome 3:14. doi: 10.1186/s40168-015-0077-6

Banik, J. J., and Brady, S. F. (2010). Recent application of metagenomic approaches toward the discovery of antimicrobials and other bioactive small molecules. Curr. Opin. Microbiol. 13, 603-609. doi: 10.1016/j.mib.2010.08.012

Beale, D. J., Karpe, A. V., and Ahmed, W. (2016). "Beyond metabolomics: a review of multi-omics-based approaches" in Microbial metabolomics (Switzerland: Springer), 289-312.

Berdy, J. (1995). Are actinomycetes exhausted as a source of secondary metabolites? Biotechnologija 7-8, 13-34.

Bérdy, J. (2012). Thoughts and facts about antibiotics: where we are now and where we are heading. J. Antibiot. 65, 385-395. doi: 10.1038/ja.2012.27

Bergmann, S., Schümann, J., Scherlach, K., Lange, C., Brakhage, A. A., and Hertweck, C. (2007). Genomics-driven discovery of PKS-NRPS hybrid metabolites from Aspergillus nidulans. Nat. Chem. Biol. 3, 213-217. doi: 10.1038/nchembio869

Besse, A., Peduzzi, J., Rebuffat, S., and Carre-Mlouka, A. (2015). Antimicrobial peptides and proteins in the face of extremes: lessons from archaeocins. Biochimie 118, 344-355. doi: 10.1016/j.biochi.2015.06.004

Bharathi, S., Radhakrishnan, M., and Balagurunathan, R. (2011). Bioprospecting of fresh water Actinobacteria: Isolation, antagonistic potential and characterization of selected isolates. India: Association of Pharmaceutical Innovators.

Bibb, M. J. (2005). Regulation of secondary metabolism in streptomycetes. Curr. Opin. Microbiol. 8, 208-215. doi: 10.1016/j.mib.2005.02.016

Biddle, J. F., Lipp, J. S., Lever, M. A., Lloyd, K. G., Sørensen, K. B., Anderson, R., et al. (2006). Heterotrophic Archaea dominate sedimentary subsurface ecosystems off Peru. Proc. Natl. Acad. Sci. 103, 3846-3851. doi: 10.1073/ pnas. 0600035103

Blin, K., Medema, M. H., Kottmann, R., Lee, S. Y., and Weber, T. (2016). The antiSMASH database, a comprehensive database of microbial secondary metabolite biosynthetic gene clusters. Nucleic Acids Res. 45, D555-D559. doi: $10.1093 / \mathrm{nar} / \mathrm{gkw} 960$

Blunt, J. W., Copp, B. R., Hu, W.-P., Munro, M., Northcote, P. T., and Prinsep, M. R. (2009). Marine natural products. Nat. Prod. Rep. 26, 170-244. doi: $10.1039 / \mathrm{b} 805113 \mathrm{p}$
Blunt, J. W., Copp, B. R., Keyzers, R. A., Munro, M. H., and Prinsep, M. R. (2016). Marine natural products. Nat. Prod. Rep. 33, 382-431. doi: 10.1039/ C5NP00156K

Boettger, D., and Hertweck, C. (2013). Molecular diversity sculpted by fungal PKS-NRPS hybrids. Chembiochem 14, 28-42. doi: 10.1002/cbic.201200624

Boolchandani, M., D'souza, A. W., and Dantas, G. (2019). Sequencing-based methods and resources to study antimicrobial resistance. Nat. Rev. Genet. 20, 356-370. doi: 10.1038/s41576-019-0108-4

Borsetto, C., and Wellington, E. M. (2017). "Bioprospecting soil Metagenomes for antibiotics" in Bioprospecting (Switzerland: Springer), 113-136.

Bose, U., Hewavitharana, A. K., Ng, Y. K., Shaw, P. N., Fuerst, J. A., and Hodson, M. P. (2015). LC-MS-based metabolomics study of marine bacterial secondary metabolite and antibiotic production in Salinispora arenicola. Mar. Drugs 13, 249-266. doi: 10.3390/md13010249

Brito, A., Gaifem, J., Ramos, V., Glukhov, E., Dorrestein, P. C., Gerwick, W. H., et al. (2015). Bioprospecting Portuguese Atlantic coast cyanobacteria for bioactive secondary metabolites reveals untapped chemodiversity. Algal Res. 9, 218-226. doi: 10.1016/j.algal.2015.03.016

Bundale, S., Begde, D., Nashikkar, N., Kadam, T., and Upadhyay, A. (2015). Optimization of culture conditions for production of bioactive metabolites by Streptomyces spp. isolated from soil. Adv. Microbiol. 5, 441-451. doi: 10.4236/aim.2015.56045

Burkholder, P. R., Pfister, R. M., and Leitz, F. H. (1966). Production of a pyrrole antibiotic by a marine bacterium. Appl. Environ. Microbiol. 14, 649-653.

Bush, K. (2010). The coming of age of antibiotics: discovery and therapeutic value. Ann. N. Y. Acad. Sci. 1213, 1-4. doi: 10.1111/j.1749-6632.2010.05872.x

Busti, E., Monciardini, P., Cavaletti, L., Bamonte, R., Lazzarini, A., Sosio, M., et al. (2006). Antibiotic-producing ability by representatives of a newly discovered lineage of actinomycetes. Microbiology 152, 675-683. doi: 10.1099/ mic. $0.28335-0$

Calabrese, E. J. (2005). Paradigm lost, paradigm found: the re-emergence of hormesis as a fundamental dose response model in the toxicological sciences. Environ. Pollut. 138, 378-411. doi: 10.1016/j.envpol.2004.10.001

Cane, D. E., and Walsh, C. T. (1999). The parallel and convergent universes of polyketide synthases and nonribosomal peptide synthetases. Chem. Biol. 6, R319-R325. doi: 10.1016/S1074-5521(00)80001-0

Cannell, R. J., Owsianka, A. M., and Walker, J. M. (1988). Results of a largescale screening programme to detect antibacterial activity from freshwater algae. Br. Phycol. J. 23, 41-44.

Carmichael, W. (1992). Cyanobacteria secondary metabolites-the cyanotoxins. J. Appl. Bacteriol. 72, 445-459. doi: 10.1111/j.1365-2672.1992.tb01858.x

Carmichael, W. W. (1994). The toxins of cyanobacteria. Sci. Am. 270, 78-86. doi: 10.1038 /scientificamerican0194-78

Chakrabarty, A., and Roy, S. (1964). Effect of trace elements on the production of pigments by a pseudomonad. Biochem. J. 93, 228-231. doi: 10.1042/ bj0930228

Chakraburtty, R., and Bibb, M. (1997). The ppGpp synthetase gene (relA) of Streptomyces coelicolor A3 (2) plays a conditional role in antibiotic production and morphological differentiation. J. Bacteriol. 179, 5854-5861. doi: 10.1128/ jb.179.18.5854-5861.1997

Chander, J., Singla, N., and Handa, U. (2015). Human cervicofacial mycetoma caused by Streptomyces griseus: first case report. J. Microbiol. Immunol. Infect. 48, 703-705. doi: 10.1016/j.jmii.2012.12.002

Chander, Y., Kumar, K., Goyal, S. M., and Gupta, S. C. (2005). Antibacterial activity of soil-bound antibiotics. J. Environ. Qual. 34, 1952-1957. doi: $10.2134 /$ jeq2005.0017

Chao, L., and Levin, B. R. (1981). Structured habitats and the evolution of anticompetitor toxins in bacteria. Proc. Natl. Acad. Sci. 78, 6324-6328. doi: 10.1073/pnas.78.10.6324

Charlop-Powers, Z., Owen, J. G., Reddy, B. V. B., Ternei, M. A., Guimarães, D. O., De Frias, U. A., et al. (2015). Global biogeographic sampling of bacterial secondary metabolism. Elife 4:e05048. doi: 10.7554/eLife.05048

Chatterjee, C., Paul, M., Xie, L., and Van Der Donk, W. A. (2005). Biosynthesis and mode of action of lantibiotics. Chem. Rev. 105, 633-684. doi: 10.1021/ cr030105v

Cheeptham, N. (2013). "Advances and challenges in studying cave microbial diversity" in Cave microbiomes: A novel resource for drug discovery (New York, USA: Springer), 1-34. 
Cheeptham, N., and Saiz-Jimenez, C. (2015). "New sources of antibiotics: caves" in Antibiotics: Current innovations and future trends (Norwich, UK: Caister Academic Press), 213-227.

Chiang, Y.-M., Oakley, B. R., Keller, N. P., and Wang, C. C. (2010). Unraveling polyketide synthesis in members of the genus Aspergillus. Appl. Microbiol. Biotechnol. 86, 1719-1736. doi: 10.1007/s00253-010-2525-3

Christiansen, G., Dittmann, E., Ordorika, L. V., Rippka, R., Herdman, M., and Börner, T. (2001). Nonribosomal peptide synthetase genes occur in most cyanobacterial genera as evidenced by their distribution in axenic strains of the PCC. Arch. Microbiol. 176, 452-458. doi: 10.1007/s002030100349

Chung, E. J., Choi, G.-G., Nam, Y.-H., and Choi, A. (2018). Draft genome sequence of Paucibacter aquatile CR182T, a strain with antimicrobial activity isolated from freshwater of Nakdong River in South Korea. Genome Announc. 6, e00194-e00118. doi: 10.1128/genomeA.00194-18

Clairoux, N., Picard, M., Brochu, A., Rousseau, N., Gourde, P., Beauchamp, D., et al. (1992). Molecular basis of the non-beta-lactamase-mediated resistance to beta-lactam antibiotics in strains of Haemophilus influenzae isolated in Canada. Antimicrob. Agents Chemother. 36, 1504-1513. doi: 10.1128/ AAC.36.7.1504

Clinical, and Institute, L. S. (2009). Performance standards for antimicrobial susceptibility testing of anaerobic bacteria: Informational supplement. Wayne, PA, USA: Clinical and Laboratory Standards Institute (CLSI).

Cohen, M. L. (1992). Epidemiology of drug resistance: implications for a post-antimicrobial era. Science 257, 1050-1055. doi: 10.1126/ science.257.5073.1050

Cole, J. J., Prairie, Y. T., Caraco, N. F., Mcdowell, W. H., Tranvik, L. J., Striegl, R. G., et al. (2007). Plumbing the global carbon cycle: integrating inland waters into the terrestrial carbon budget. Ecosystems 10, 172-185. doi: 10.1007/s10021-006-9013-8

Cole, J. R., Wang, Q., Cardenas, E., Fish, J., Chai, B., Farris, R. J., et al. (2008). The ribosomal database project: improved alignments and new tools for rRNA analysis. Nucleic Acids Res. 37, D141-D145. doi: 10.1007/s10021-006-9013-8

Coleman, M. L., Sullivan, M. B., Martiny, A. C., Steglich, C., Barry, K., Delong, E. F., et al. (2006). Genomic islands and the ecology and evolution of Prochlorococcus. Science 311, 1768-1770. doi: 10.1126/science.1122050

Colquhoun, J. A., Heald, S. C., Li, L., Tamaoka, J., Kato, C., Horikoshi, K., et al. (1998a). Taxonomy and biotransformation activities of some deep-sea actinomycetes. Extremophiles 2, 269-277.

Colquhoun, J. A., Mexson, J., Goodfellow, M., Ward, A. C., Horikoshi, K., and Bull, A. T. (1998b). Novel rhodococci and other mycolate actinomycetes from the deep sea. Antonie Van Leeuwenhoek 74, 27-40.

Conway, K. R., and Boddy, C. N. (2012). ClusterMine360: a database of microbial PKS/NRPS biosynthesis. Nucleic Acids Res. 41, D402-D407. doi: 10.1093/ nar/gks993

Cornforth, D. M., and Foster, K. R. (2015). Antibiotics and the art of bacterial war. Proc. Natl. Acad. Sci. 112, 10827-10828. doi: 10.1073/pnas.1513608112

Coyte, K. Z., Schluter, J., and Foster, K. R. (2015). The ecology of the microbiome: networks, competition, and stability. Science 350, 663-666. doi: 10.1126/ science.aad 2602

Crits-Christoph, A., Diamond, S., Butterfield, C. N., Thomas, B. C., and Banfield, J. F. (2018). Novel soil bacteria possess diverse genes for secondary metabolite biosynthesis. Nature 558, 440-444. doi: 10.1038/s41586-018-0207-y

Crosa, J. H., and Walsh, C. T. (2002). Genetics and assembly line enzymology of siderophore biosynthesis in bacteria. Microbiol. Mol. Biol. Rev. 66, 223-249. doi: 10.1128 /MMBR.66.2.223-249.2002

Cross, T. (1968). Thermophilic actinomycetes. J. Appl. Microbiol. 31, 36-53.

Cross, T. (1981). Aquatic actinomycetes: a critical survey of the occurrence, growth and role of actinomycetes in aquatic habitats. J. Appl. Microbiol. 50, 397-423.

Culligan, E. P., Sleator, R. D., Marchesi, J. R., and Hill, C. (2014). Metagenomics and novel gene discovery: promise and potential for novel therapeutics. Virulence 5, 399-412. doi: 10.4161/viru.27208

D’agostino, P. M., Woodhouse, J. N., Makower, A. K., Yeung, A. C., Ongley, S. E., Micallef, M. L., et al. (2016). Advances in genomics, transcriptomics and proteomics of toxin-producing cyanobacteria. Environ. Microbiol. Rep. 8, 3-13. doi: 10.1111/1758-2229.12366

Daniel, R. (2004). The soil metagenome-a rich resource for the discovery of novel natural products. Curr. Opin. Biotechnol. 15, 199-204. doi: 10.1016/j. copbio.2004.04.005
Danilovich, M. E., Sánchez, L. A., Acosta, F., and Delgado, O. D. (2018). Antarctic bioprospecting: in pursuit of microorganisms producing new antimicrobials and enzymes. Polar Biol. 41, 1417-1433. doi: 10.1007/s00300-018-2295-4

David, B., Wolfender, J.-L., and Dias, D. A. (2015). The pharmaceutical industry and natural products: historical status and new trends. Phytochem. Rev. 14, 299-315. doi: 10.1007/s11101-014-9367-z

Davies, J. (2006). Are antibiotics naturally antibiotics? J. Ind. Microbiol. Biotechnol. 33, 496-499. doi: 10.1007/s10295-006-0112-5

Davies, J., Spiegelman, G. B., and Yim, G. (2006). The world of subinhibitory antibiotic concentrations. Curr. Opin. Microbiol. 9, 445-453. doi: 10.1016/j. mib.2006.08.006

Davis, B., Luger, S., and Tai, P. (1986). Role of ribosome degradation in the death of starved Escherichia coli cells. J. Bacteriol. 166, 439-445. doi: 10.1128/ jb.166.2.439-445.1986

Demain, A. L., Gómez-Ortiz, B., Ruiz-Villafán, B., Rodríguez-Sanoja, R., and Sánchez, S. (2019). Recent findings of molecules with anti-infective activity: screening of non-conventional sources. Curr. Opin. Pharmacol. 48, 40-47. doi: 10.1016/j.coph.2019.04.003

Demay, J., Bernard, C., Reinhardt, A., and Marie, B. (2019). Natural products from cyanobacteria: focus on beneficial activities. Mar. Drugs 17:320. doi: $10.3390 / \mathrm{md} 17060320$

Denicola, D. M., and Lellock, A. J. (2015). Nutrient limitation of algal periphyton in streams along an acid mine drainage gradient. J. Phycol. 51, 739-749. doi: $10.1111 /$ jpy.12315

Dersch, P., Khan, M. A., Mühlen, S., and Görke, B. (2017). Roles of regulatory RNAs for antibiotic resistance in bacteria and their potential value as novel drug targets. Front. Microbiol. 8:803. doi: 10.3389/fmicb.2017.00803

Dias, D. A., Urban, S., and Roessner, U. (2012). A historical overview of natural products in drug discovery. Meta 2, 303-336. doi: 10.3390/ metabo2020303

Ding, Z. G., Li, M. G., Zhao, J. Y., Ren, J., Huang, R., Xie, M. J., et al. (2010). Naphthospironone a: an unprecedented and highly functionalized polycyclic metabolite from an alkaline mine waste extremophile. Chem. Eur. J. 16, 3902-3905. doi: 10.1002/chem.200903198

Dixon, M. (1953). The effect of $\mathrm{pH}$ on the affinities of enzymes for substrates and inhibitors. Biochem. J. 55, 161-170. doi: 10.1042/bj0550161

Donowitz, G. R., and Mandell, G. L. (1988). Beta-lactam antibiotics. N. Engl. J. Med. 318, 419-426. doi: 10.1056/NEJM198802183180706

Drews, J. (2000). Drug discovery: a historical perspective. Science 287, 1960 1964. doi: 10.1126/science.287.5460.1960

Du, L., Sánchez, C., Chen, M., Edwards, D. J., and Shen, B. (2000). The biosynthetic gene cluster for the antitumor drug bleomycin from Streptomyces verticillus ATCC15003 supporting functional interactions between nonribosomal peptide synthetases and a polyketide synthase. Chem. Biol. 7, 623-642. doi: 10.1016/S1074-5521(00)00011-9

Duff, D. A., Bruce, D., and Antia, N. (1966). The antibacterial activity of marine planktonic algae. Can. J. Microbiol. 12, 877-884. doi: 10.1139/m66-120

Dundore-Arias, J. P., Felice, L., Dill-Macky, R., and Kinkel, L. L. (2019). Carbon amendments induce shifts in nutrient use, inhibitory, and resistance phenotypes among soilborne Streptomyces. Front. Microbiol. 10:498. doi: 10.3389/ fmicb.2019.00498

Dwyer, D. J., Collins, J. J., and Walker, G. C. (2015). Unraveling the physiological complexities of antibiotic lethality. Annu. Rev. Pharmacol. Toxicol. 55, 313332. doi: 10.1146/annurev-pharmtox-010814-124712

Ehrenreich, I. M., Waterbury, J. B., and Webb, E. A. (2005). Distribution and diversity of natural product genes in marine and freshwater cyanobacterial cultures and genomes. Appl. Environ. Microbiol. 71, 7401-7413. doi: 10.1128/ AEM.71.11.7401-7413.2005

Eisfeld, K. (2009). "Non-ribosomal peptide synthetases of fungi” in Physiology and genetics (Berlin, Heidelberg, Germany: Springer), 305-330.

El-Deeb, B., Fayez, K., and Gherbawy, Y. (2013). Isolation and characterization of endophytic bacteria from Plectranthus tenuiflorus medicinal plant in Saudi Arabia desert and their antimicrobial activities. J. Plant Interact. 8, 56-64. doi: 10.1080/17429145.2012.680077

Emmerson, A., and Jones, A. (2003). The quinolones: decades of development and use. J. Antimicrob. Chemother. 51, 13-20. doi: 10.1093/jac/dkg208

Epand, R. M., and Vogel, H. J. (1999). Diversity of antimicrobial peptides and their mechanisms of action. Biochim. Biophys. Acta 1462, 11-28. doi: 10.1016/ S0005-2736(99)00198-4 
Fergus, C. (1964). Thermophilic and thermotolerant molds and actinomycetes of mushroom compost during peak heating. Mycologia 56, 267-284.

Fichez, R. (1990). Decrease in allochthonous organic inputs in dark submarine caves, connection with lowering in benthic community richness. Hydrobiologia 207, 61-69. doi: 10.1007/BF00041441

Fiedler, H.-P., Bruntner, C., Bull, A. T., Ward, A. C., Goodfellow, M., Potterat, O., et al. (2005). Marine actinomycetes as a source of novel secondary metabolites. Antonie Van Leeuwenhoek 87, 37-42. doi: 10.1007/s10482-004-6538-8

Fisch, K. M. (2013). Biosynthesis of natural products by microbial iterative hybrid PKS-NRPS. RSC Adv. 3, 18228-18247. doi: 10.1039/c3ra42661k

Fitzpatrick, F., Humphreys, H., Smyth, E., Kennedy, C., and O'gara, J. (2002). Environmental regulation of biofilm formation in intensive care unit isolates of Staphylococcus epidermidis. J. Hosp. Infect. 52, 212-218. doi: 10.1053/jhin.2002.1309

Fontaine, S., Mariotti, A., and Abbadie, L. (2003). The priming effect of organic matter: a question of microbial competition? Soil Biol. Biochem. 35, 837-843. doi: 10.1016/S0038-0717(03)00123-8

Francis, C. A., Roberts, K. J., Beman, J. M., Santoro, A. E., and Oakley, B. B. (2005). Ubiquity and diversity of ammonia-oxidizing archaea in water columns and sediments of the ocean. Proc. Natl. Acad. Sci. 102, 14683-14688. doi: 10.1073/pnas.0506625102

Frangeul, L., Quillardet, P., Castets, A.-M., Humbert, J.-F., Matthijs, H. C., Cortez, D., et al. (2008). Highly plastic genome of Microcystis aeruginosa PCC 7806, a ubiquitous toxic freshwater cyanobacterium. BMC Genomics 9:274. doi: 10.1186/1471-2164-9-274

Franzosa, E. A., Hsu, T., Sirota-Madi, A., Shafquat, A., Abu-Ali, G., Morgan, X. C., et al. (2015). Sequencing and beyond: integrating molecularomics' for microbial community profiling. Nat. Rev. Microbiol. 13, 360-372. doi: $10.1038 /$ nrmicro3451

Fredrickson, A., and Stephanopoulos, G. (1981). Microbial competition. Science 213, 972-979. doi: 10.1126/science.7268409

Gagen, E. J., Huber, H., Meador, T., Hinrichs, K.-U., and Thomm, M. (2013). A novel cultivation-based approach for understanding the miscellaneous Crenarchaeotic group (MCG) Archaea from sedimentary ecosystems. Appl. Environ. Microbiol. 79, 6400-6406. doi: 10.1128/AEM.02153-13

Gallo, A., Ferrara, M., and Perrone, G. (2013). Phylogenetic study of polyketide synthases and nonribosomal peptide synthetases involved in the biosynthesis of mycotoxins. Toxins 5, 717-742. doi: 10.3390/toxins5040717

Garcia, R., La Clair, J., and Müller, R. (2018). Future directions of marine myxobacterial natural product discovery inferred from metagenomics. Mar. Drugs 16:303. doi: 10.3390/md16090303

Ghosh, S., Kuisiene, N., and Cheeptham, N. (2017). The cave microbiome as a source for drug discovery: reality or pipe dream? Biochem. Pharmacol. 134, 18-34. doi: 10.1016/j.bcp.2016.11.018

Ghoul, M., and Mitri, S. (2016). The ecology and evolution of microbial competition. Trends Microbiol. 24, 833-845. doi: 10.1016/j.tim.2016.06.011

Gilbert, P., Collier, P. J., and Brown, M. (1990). Influence of growth rate on susceptibility to antimicrobial agents: biofilms, cell cycle, dormancy, and stringent response. Antimicrob. Agents Chemother. 34, 1865-1868. doi: 10.1128/ AAC. 34.10 .1865

Gillespie, S. H., Basu, S., Dickens, A. L., O'sullivan, D. M., and Mchugh, T. D. (2005). Effect of subinhibitory concentrations of ciprofloxacin on Mycobacterium fortuitum mutation rates. J. Antimicrob. Chemother. 56, 344-348. doi: 10.1093/ jac/dki191

Gillooly, J. F., Brown, J. H., West, G. B., Savage, V. M., and Charnov, E. L. (2001). Effects of size and temperature on metabolic rate. Science 293, 2248-2251. doi: 10.1126/science.1061967

Goodfellow, M., and Williams, S. (1983). Ecology of actinomycetes. Annu. Rev. Microbiol. 37, 189-216. doi: 10.1146/annurev.mi.37.100183.001201

Gottlieb, D. (1976). The production and role of antibiotics in soil. J. Antibiot. 29, 987-1000. doi: 10.7164/antibiotics.29.987

Grabowski, E. J. (2005). Enantiopure drug synthesis: from methyldopa to imipenem to efavirenz. Chirality 17, S249-S259. doi: 10.1002/chir.20143

Gradnigo, J. S., Somerville, G. A., Huether, M. J., Kemmy, R. J., Johnson, C. M., Oliver, M. G., et al. (2016). Genome sequence of Streptomyces aureofaciens ATCC strain 10762. Genome Announc. 4, e00615-e00616. doi: 10.1128/ genomeA.00615-16

Groth, I., Schumann, P., Schuetze, B., Augsten, K., Kramer, I., and Stackebrandt, E. (1999). Beutenbergia cavernae gen. nov., sp. nov., an L-lysine-containing actinomycete isolated from a cave. Int. J. Syst. Evol. Microbiol. 49, 1733-1740.
Haefner, B. (2003). Drugs from the deep: marine natural products as drug candidates. Drug Discov. Today 8, 536-544. doi: 10.1016/S1359-6446(03)02713-2

Haferburg, G., Reinicke, M., Merten, D., Büchel, G., and Kothe, E. (2007). Microbes adapted to acid mine drainage as source for strains active in retention of aluminum or uranium. J. Geochem. Explor. 92, 196-204. doi: 10.1016/j.gexplo.2006.08.011

Handelsman, J., Rondon, M. R., Brady, S. F., Clardy, J., and Goodman, R. M. (1998). Molecular biological access to the chemistry of unknown soil microbes: a new frontier for natural products. Chem. Biol. 5, R245-R249. doi: 10.1016/ S1074-5521(98)90108-9

Hardin, G. (1960). The competitive exclusion principle. Science 131, 1292-1297. doi: $10.1126 /$ science.131.3409.1292

Harms, H., König, G. M., and Schäberle, T. F. (2017). "Production of antimicrobial compounds by fermentation" in Antibiotics (New York, USA: Springer), $49-61$.

Harvey, A. L. (2008). Natural products in drug discovery. Drug Discov. Today 13, 894-901. doi: 10.1016/j.drudis.2008.07.004

Harvey, A. L., Edrada-Ebel, R., and Quinn, R. J. (2015). The re-emergence of natural products for drug discovery in the genomics era. Nat. Rev. Drug Discov. 14, 111-129. doi: $10.1038 / \operatorname{nrd} 4510$

Hays, E. E., Wells, I. C., Katzman, P. A., Cain, C., Jacobs, F. A., Thayer, S. A., et al. (1945). Antibiotic substances produced by Pseu-domonas aeruginosa. Biol. Chem. 159, 725-750.

Helfrich, E. J., Reiter, S., and Piel, J. (2014). Recent advances in genome-based polyketide discovery. Curr. Opin. Biotechnol. 29, 107-115. doi: 10.1016/j. copbio.2014.03.004

Henderson-Begg, S. K., Livermore, D. M., and Hall, L. M. (2006). Effect of subinhibitory concentrations of antibiotics on mutation frequency in Streptococcus pneumoniae. J. Antimicrob. Chemother. 57, 849-854. doi: 10.1093/ $\mathrm{jac} / \mathrm{dkl} 064$

Herrero, A., Muro-Pastor, A. M., and Flores, E. (2001). Nitrogen control in cyanobacteria. J. Bacteriol. 183, 411-425. doi: 10.1128/JB.183.2.411-425.2001

Hibbing, M. E., Fuqua, C., Parsek, M. R., and Peterson, S. B. (2010). Bacterial competition: surviving and thriving in the microbial jungle. Nat. Rev. Microbiol. 8, 15-25. doi: 10.1038/nrmicro2259

Hill, P., Heberlig, G., and Boddy, C. (2017). Sampling terrestrial environments for bacterial polyketides. Molecules 22:707. doi: 10.3390/molecules22050707

Hiraoka, S., Yang, C.-C., and Iwasaki, W. (2016). Metagenomics and bioinformaticsr in microbial ecology: current status and beyond. Microbes Environ. 31, 204-212. doi: 10.1264/jsme2.ME16024

Hodges, T. W., Slattery, M., and Olson, J. B. (2012). Unique actinomycetes from marine caves and coral reef sediments provide novel PKS and NRPS biosynthetic gene clusters. Mar. Biotechnol. 14, 270-280. doi: 10.1007/ s10126-011-9410-7

Hoffman, L. R., D’argenio, D. A., Maccoss, M. J., Zhang, Z., Jones, R. A., and Miller, S. I. (2005). Aminoglycoside antibiotics induce bacterial biofilm formation. Nature 436, 1171-1175. doi: 10.1038/nature03912

Hogsden, K. L., and Harding, J. S. (2011). Consequences of acid mine drainage for the structure and function of benthic stream communities: a review. Freshwater Sci. 31, 108-120. doi: 10.1899/11-091.1

Hook, W., and Plante, C. (2019). Antibiotic production by intertidal sedimentary and porewater bacteria and the characterization of their prevalence in situ. Plankton Benthos Res. 14, 197-205. doi: 10.3800/pbr.14.197

Hopwood, D. A. (1999). Forty years of genetics with Streptomyces: from in vivo through in vitro to in silico. Microbiology 145, 2183-2202. doi: 10.1099/00221287-145-9-2183

Hoshino, T., and Inagaki, F. (2019). Abundance and distribution of Archaea in the subseafloor sedimentary biosphere. ISME J. 13, 227-231. doi: 10.1038/ s41396-018-0253-3

Houbraken, J., Frisvad, J. C., and Samson, R. A. (2011). Fleming's penicillin producing strain is not Penicillium chrysogenum but P. rubens. IMA Fungus 2, 87-95. doi: 10.5598/imafungus.2011.02.01.12

Hozzein, W. N., Rabie, W., and Ali, M. I. A. (2011). Screening the Egyptian desert actinomycetes as candidates for new antimicrobial compounds and identification of a new desert Streptomyces strain. Afr. J. Biotechnol. 10, 2295-2301.

Huber, J. A., Welch, D. B. M., Morrison, H. G., Huse, S. M., Neal, P. R., Butterfield, D. A., et al. (2007). Microbial population structures in the deep marine biosphere. Science 318, 97-100. doi: 10.1126/science.1146689 
Hug, L. A., Baker, B. J., Anantharaman, K., Brown, C. T., Probst, A. J., Castelle, C. J., et al. (2016). A new view of the tree of life. Nat. Microbiol. 1:16048. doi: $10.1038 /$ nmicrobiol.2016.48

Hughes, C. C., Prieto-Davo, A., Jensen, P. R., and Fenical, W. (2008). The marinopyrroles, antibiotics of an unprecedented structure class from a marine Streptomyces sp. Org. Lett. 10, 629-631. doi: 10.1021/ol702952n

Hutchinson, G. E. (1961). The paradox of the plankton. Am. Nat. 95, 137-145. doi: $10.1086 / 282171$

Imada, C., Koseki, N., Kamata, M., Kobayashi, T., and Hamada-Sato, N. (2007). Isolation and characterization of antibacterial substances produced by marine actinomycetes in the presence of seawater. Actinomycetologica 21, 27-31. doi: $10.3209 /$ saj.saj210104

Inagaki, F., Hinrichs, K.-U., Kubo, Y., Bowles, M. W., Heuer, V. B., Hong, W.-L., et al. (2015). Exploring deep microbial life in coal-bearing sediment down to $\sim 2.5 \mathrm{~km}$ below the ocean floor. Science $349,420-424$. doi: 10.1126 / science.aaa 6882

Indraningrat, A., Smidt, H., and Sipkema, D. (2016). Bioprospecting spongeassociated microbes for antimicrobial compounds. Mar. Drugs 14:87. doi: $10.3390 / \mathrm{md} 14050087$

Jamet, A., and Nassif, X. (2015). New players in the toxin field: polymorphic toxin systems in bacteria. MBio 6, e00285-e00215. doi: 10.1128/mBio.00285-15

Jaume, D., and Boxshall, G. (2009). Life in extreme ocean environments: anchialine caves. Marine Ecol. EOLSS, 230-251.

Jørgensen, B. B., and Boetius, A. (2007). Feast and famine-microbial life in the deep-sea bed. Nat. Rev. Microbiol. 5, 770-781. doi: 10.1038/nrmicro1745

Jørgensen, B. B., and Marshall, I. P. (2016). Slow microbial life in the seabed. Annu. Rev. Mar. Sci. 8, 311-332. doi: 10.1146/annurev-marine-010814-015535

Jose, P. A., and Jebakumar, S. R. D. (2014). Unexplored hypersaline habitats are sources of novel actinomycetes. Front. Microbiol. 5:242. doi: 10.3389/ fmicb.2014.00242

Juhas, M., Eberl, L., and Glass, J. I. (2011). Essence of life: essential genes of minimal genomes. Trends Cell Biol. 21, 562-568. doi: 10.1016/j.tcb.2011.07.005

Jungbluth, S. P., Amend, J. P., and Rappé, M. S. (2017). Metagenome sequencing and 98 microbial genomes from Juan de Fuca ridge flank subsurface fluids. Scientific data 4:170037. doi: 10.1038/sdata.2017.80

Jurado, V., Groth, I., Gonzalez, J. M., Laiz, L., and Saiz-Jimenez, C. (2005). Agromyces subbeticus sp. nov., isolated from a cave in southern Spain. Int. J. Syst. Evol. Microbiol. 55, 1897-1901. doi: 10.1099/ijs.0.63637-0

Kaplan, K., and Weinstein, L. (1968). Lincomycin. Pediatr. Clin. N. Am. 15, 131-139. doi: 10.1016/S0031-3955(16)32094-6

Karner, M. B., Delong, E. F., and Karl, D. M. (2001). Archaeal dominance in the mesopelagic zone of the Pacific Ocean. Nature 409, 507-510. doi: $10.1038 / 35054051$

Katz, L., and Baltz, R. H. (2016). Natural product discovery: past, present, and future. J. Ind. Microbiol. Biotechnol. 43, 155-176. doi: 10.1007/s10295-015-1723-5

Kealey, C., Creaven, C., Murphy, C., and Brady, C. (2017). New approaches to antibiotic discovery. Biotechnol. Lett. 39, 805-817. doi: 10.1007/s10529-017-2311-8

Keller, N. P., Turner, G., and Bennett, J. W. (2005). Fungal secondary metabolismfrom biochemistry to genomics. Nat. Rev. Microbiol. 3, 937-947. doi: 10.1038/ nrmicro1286

Kendig, E. L., Le, H. H., and Belcher, S. M. (2010). Defining hormesis: evaluation of a complex concentration response phenomenon. Int. J. Toxicol. 29, 235246. doi: 10.1177/1091581810363012

Keren, I., Wu, Y., Inocencio, J., Mulcahy, L. R., and Lewis, K. (2013). Killing by bactericidal antibiotics does not depend on reactive oxygen species. Science 339, 1213-1216. doi: 10.1126/science.1232688

Kerr, B., Riley, M. A., Feldman, M. W., and Bohannan, B. J. (2002). Local dispersal promotes biodiversity in a real-life game of rock-paper-scissors. Nature 418, 171. doi: 10.1038/nature00823

Khaldi, N., Seifuddin, F. T., Turner, G., Haft, D., Nierman, W. C., Wolfe, K. H., et al. (2010). SMURF: genomic mapping of fungal secondary metabolite clusters. Fungal Genet. Biol. 47, 736-741. doi: 10.1016/j.fgb.2010.06.003

Killham, K. (1994). Soil ecology. Cambridge, UK: Cambridge University Press.

Kim, M., Lee, K.-H., Yoon, S.-W., Kim, B.-S., Chun, J., and Yi, H. (2013). Analytical tools and databases for metagenomics in the next-generation sequencing era. Genomics Informat. 11, 102-113. doi: 10.5808/ GI.2013.11.3.102

Kim, T. K., Hewavitharana, A. K., Shaw, P. N., and Fuerst, J. A. (2006). Discovery of a new source of rifamycin antibiotics in marine sponge actinobacteria by phylogenetic prediction. Appl. Environ. Microbiol. 72, 2118-2125. doi: 10.1128/AEM.72.3.2118-2125.2006

Kim, W., Zhu, W., Hendricks, G. L., Van Tyne, D., Steele, A. D., Keohane, C. E., et al. (2018). A new class of synthetic retinoid antibiotics effective against bacterial persisters. Nature 556, 103-107. doi: 10.1038/nature26157

Kirkpatrick, J. B., Walsh, E. A., and D’hondt, S. (2016). Fossil DNA persistence and decay in marine sediment over hundred-thousand-year to million-year time scales. Geology 44, 615-618. doi: 10.1130/G37933.1

Koch, M., Best, P., Farnham, G., Kiernan, M., Bishop, A., Warburton, P., et al. (2019). Characterisation of the microbiome for two hexactinellid sponges and purification of associated antimicrobial agents from their resident microbes. Access Microbiol. 1:1. doi: 10.1099/acmi.ac2019.po0410

Kuenen, J. G., and Bos, P. (1989). "Habitats and ecological niches of chemolitho (auto) trophic bacteria" in Autotrophic Bacteria (Berlin: Springer), 53-80.

Kumar, A., and Ting, Y.-P. (2013). Effect of sub-inhibitory antibacterial stress on bacterial surface properties and biofilm formation. Colloids Surf. B: Biointerfaces 111, 747-754. doi: 10.1016/j.colsurfb.2013.07.011

Kumar, V., and Tiwari, S. K. (2019). "Halocin diversity among Halophilic Archaea and their applications" in Microbial diversity in ecosystem sustainability and biotechnological applications (Singapore: Springer), 497-532.

Kumar, V. V., and Anthony, S. P. (2016). "Antimicrobial studies of metal and metal oxide nanoparticles" in Surface chemistry of Nanobiomaterials (Amsterdam, Netherlands: Elsevier), 265-300.

Kysela, D. T., Palacios, C., and Sogin, M. L. (2005). Serial analysis of V6 ribosomal sequence tags (SARST-V6): a method for efficient, high-throughput analysis of microbial community composition. Environ. Microbiol. 7, 356-364. doi: 10.1111/j.1462-2920.2004.00712.x

Langseth, M. G., Becker, K., Von Herzen, R. P., and Schultheiss, P. (1992). Heat and fluid flux through sediment on the western flank of the mid-Atlantic ridge: a hydrogeological study of north pond. Geophys. Res. Lett. 19, 517-520. doi: 10.1029/92GL00079

Laskaris, P., Tolba, S., Calvo-Bado, L., and Wellington, L. (2010). Coevolution of antibiotic production and counter-resistance in soil bacteria. Environ. Microbiol. 12, 783-796. doi: 10.1111/j.1462-2920.2009.02125.x

Lau, M. C., Cameron, C., Magnabosco, C., Brown, C. T., Schilkey, F., Grim, S., et al. (2014). Phylogeny and phylogeography of functional genes shared among seven terrestrial subsurface metagenomes reveal $\mathrm{N}$-cycling and microbial evolutionary relationships. Front. Microbiol. 5:531. doi: 10.3389/ fmicb.2014.00531

Lazzarini, A., Cavaletti, L., Toppo, G., and Marinelli, F. (2000). Rare genera of actinomycetes as potential producers of new antibiotics. Antonie Van Leeuwenhoek 78, 399-405. doi: 10.1023/A:1010287600557

Leary, D., Vierros, M., Hamon, G., Arico, S., and Monagle, C. (2009). Marine genetic resources: a review of scientific and commercial interest. Mar. Policy 33, 183-194. doi: 10.1016/j.marpol.2008.05.010

Lee, S. D., Kang, S.-O., and Hah, Y. C. (2000). Catellatospora koreensis sp. nov., a novel actinomycete isolated from a gold-mine cave. Int. J. Syst. Evol. Microbiol. 50, 1103-1111. doi: 10.1099/00207713-50-3-1103

Leininger, S., Urich, T., Schloter, M., Schwark, L., Qi, J., Nicol, G. W., et al. (2006). Archaea predominate among ammonia-oxidizing prokaryotes in soils. Nature 442, 806-809. doi: 10.1038/nature04983

Lewis, K. (2007). Persister cells, dormancy and infectious disease. Nat. Rev. Microbiol. 5, 48-56. doi: 10.1038/nrmicro1557

Lewis, K. (2008). "Multidrug tolerance of biofilms and persister cells" in Bacterial biofilms (Berlin, Heidelberg, Germany: Springer), 107-131.

Lewis, K. (2010). Persister cells. Annu. Rev. Microbiol. 64, 357-372. doi: 10.1146/ annurev.micro.112408.134306

Lewis, K. (2013). Platforms for antibiotic discovery. Nat. Rev. Drug Discov. 12, 371-387. doi: $10.1038 /$ nrd3975

Lewis, K. (2017). New approaches to antimicrobial discovery. Biochem. Pharmacol. 134, 87-98. doi: 10.1016/j.bcp.2016.11.002

Li, J., Xie, S., Ahmed, S., Wang, F., Gu, Y., Zhang, C., et al. (2017). Antimicrobial activity and resistance: influencing factors. Front. Pharmacol. 8:364. doi: 10.3389/fphar.2017.00364

Li, J. W.-H., and Vederas, J. C. (2009). Drug discovery and natural products: end of an era or an endless frontier? Science 325, 161-165. doi: 10.1126/ science. 1168243

Ligon, B. L. (2004). "Penicillin: its discovery and early development" in Seminars in pediatric infectious diseases (Amsterdam, Netherlands: Elsevier), 52-57. 
Linares, J. F., Gustafsson, I., Baquero, F., and Martinez, J. (2006). Antibiotics as intermicrobial signaling agents instead of weapons. Proc. Natl. Acad. Sci. 103, 19484-19489. doi: 10.1073/pnas.0608949103

Lindequist, U. (2016). Marine-derived pharmaceuticals-challenges and opportunities. Biomol. Ther. 24, 561-571. doi: 10.4062/biomolther.2016.181

Lipp, J. S., Morono, Y., Inagaki, F., and Hinrichs, K.-U. (2008). Significant contribution of Archaea to extant biomass in marine subsurface sediments. Nature 454, 991-994. doi: 10.1038/nature07174

Liu, G., Chater, K. F., Chandra, G., Niu, G., and Tan, H. (2013). Molecular regulation of antibiotic biosynthesis in Streptomyces. Microbiol. Mol. Biol. Rev. 77, 112-143. doi: 10.1128/MMBR.00054-12

Liu, L., Zhang, Z., Shao, C.-L., Wang, J.-L., Bai, H., and Wang, C.-Y. (2015). Bioinformatical analysis of the sequences, structures and functions of fungal polyketide synthase product template domains. Sci. Rep. 5:10463. doi: 10.1038/ srep 18582

Long, P. E., Williams, K. H., Hubbard, S. S., and Banfield, J. F. (2016). Microbial metagenomics reveals climate-relevant subsurface biogeochemical processes. Trends Microbiol. 24, 600-610. doi: 10.1016/j.tim.2016.04.006

Ma, S. M., Li, J. W.-H., Choi, J. W., Zhou, H., Lee, K. M., Moorthie, V. A., et al. (2009). Complete reconstitution of a highly reducing iterative polyketide synthase. Science 326, 589-592. doi: 10.1126/science.1175602

Machado, H., Sonnenschein, E. C., Melchiorsen, J., and Gram, L. (2015). Genome mining reveals unlocked bioactive potential of marine Gram-negative bacteria. BMC Genomics 16:158. doi: 10.1186/s12864-015-1365-z

Maciejewska, M., Adam, D., Martinet, L., Naômé, A., Całusińska, M., Delfosse, P., et al. (2016). A phenotypic and genotypic analysis of the antimicrobial potential of cultivable Streptomyces isolated from cave moonmilk deposits. Front. Microbiol. 7:1455. doi: 10.3389/fmicb.2016.01455

Maciejewska, M., Adam, D., Naômé, A., Martinet, L., Tenconi, E., Całusińska, M., et al. (2017). Assessment of the potential role of Streptomyces in cave moonmilk formation. Front. Microbiol. 8:1181. doi: 10.3389/fmicb.2017.01181

Madhumathi, V., Deepa, P., Jeyachandran, S., Manoharan, C., and Vijayakumar, S. (2011). Antimicrobial activity of cyanobacteria isolated from freshwater lake. Int. J. Microbiol. Res. 2, 213-216. doi: 10.1128/mBio.00715-19

Magnabosco, C., Tekere, M., Lau, M. C., Linage, B., Kuloyo, O., Erasmus, M., et al. (2014). Comparisons of the composition and biogeographic distribution of the bacterial communities occupying south African thermal springs with those inhabiting deep subsurface fracture water. Front. Microbiol. 5:679. doi: 10.3389/fmicb.2014.00679

Mahajan, G. B., and Balachandran, L. (2012). Antibacterial agents from actinomycetes-a review. Front. Biosci. 4, 240-253. doi: 10.2741/e373

Makarova, K. S., Wolf, Y. I., Karamycheva, S., Zhang, D., Aravind, L., and Koonin, E. V. (2019). Antimicrobial peptides, polymorphic toxins, and selfnonself recognition systems in Archaea: an untapped armory for intermicrobial conflicts. MBio 10, e00715-e00719. doi: 10.1128/mBio.00715-19

Mandal, S. M., Roy, A., Ghosh, A. K., Hazra, T. K., Basak, A., and Franco, O. L. (2014). Challenges and future prospects of antibiotic therapy: from peptides to phages utilization. Front. Pharmacol. 5:105. doi: 10.3389/fphar.2014.00105

Manzoni, C., Kia, D. A., Vandrovcova, J., Hardy, J., Wood, N. W., Lewis, P. A., et al. (2016). Genome, transcriptome and proteome: the rise of omics data and their integration in biomedical sciences. Brief. Bioinform. 19, 286-302. doi: 10.1093/bib/bbw114

Marchado, H. (2016). Marine bacterial Genomics-An Ocean of opportunity: Denmark: Technical University of Denmark Systems Biology.

Marti, S., Puig, C., Merlos, A., Viñas, M., De Jonge, M. I., Liñares, J., et al. (2017). Bacterial lysis through interference with peptidoglycan synthesis increases biofilm formation by nontypeable haemophilus influenzae. Msphere 2, e00329-e00316. doi: 10.1128/mSphere.00329-16

Martins, R. F., Ramos, M. F., Herfindal, L., Sousa, J. A., Skærven, K., and Vasconcelos, V. M. (2008). Antimicrobial and cytotoxic assessment of marine cyanobacteria-Synechocystis and Synechococcus. Mar. Drugs 6, 1-11. doi: 10.3390/md6010001

Martiny, J. B. H., Bohannan, B. J., Brown, J. H., Colwell, R. K., Fuhrman, J. A., Green, J. L., et al. (2006). Microbial biogeography: putting microorganisms on the map. Nat. Rev. Microbiol. 4, 102-112. doi: 10.1038/nrmicrol341

Masschelein, J., Mattheus, W., Gao, L.-J., Moons, P., Van Houdt, R., Uytterhoeven, B., et al. (2013). A PKS/NRPS/FAS hybrid gene cluster from Serratia plymuthica RVH1 encoding the biosynthesis of three broad spectrum, zeamine-related antibiotics. PLoS One 8:e54143. doi: 10.1371/journal.pone.0054143
Mathieu, A., Fleurier, S., Frénoy, A., Dairou, J., Bredeche, M.-F., Sanchez-Vizuete, P., et al. (2016). Discovery and function of a general core hormetic stress response in $E$. coli induced by sublethal concentrations of antibiotics. Cell Rep. 17, 46-57. doi: 10.1016/j.celrep.2016.09.001

Maurya, S. K., and Mishra, R. (2019). "Importance of bioinformatics in genome Mining of Cyanobacteria for production of bioactive compounds" in Cyanobacteria (Amsterdam, Netherlands: Elsevier), 477-506.

Mazard, S., Penesyan, A., Ostrowski, M., Paulsen, I., and Egan, S. (2016). Tiny microbes with a big impact: the role of cyanobacteria and their metabolites in shaping our future. Mar. Drugs 14:97. doi: 10.3390/md14050097

Mcdonald, L. A., Capson, T. L., Krishnamurthy, G., Ding, W.-D., Ellestad, G. A., Bernan, V. S., et al. (1996). Namenamicin, a new enediyne antitumor antibiotic from the marine ascidian Polysyncraton lithostrotum. J. Am. Chem. Soc. 118, 10898-10899. doi: 10.1021/ja961122n

Medema, M. H., Blin, K., Cimermancic, P., De Jager, V., Zakrzewski, P., Fischbach, M. A., et al. (2011). antiSMASH: rapid identification, annotation and analysis of secondary metabolite biosynthesis gene clusters in bacterial and fungal genome sequences. Nucleic Acids Res. 39, W339-W346. doi: 10.1093/nar/gkr466

Medema, M. H., Kottmann, R., Yilmaz, P., Cummings, M., Biggins, J. B., Blin, K., et al. (2015). Minimum information about a biosynthetic gene cluster. Nat. Chem. Biol. 11, 625-631. doi: 10.1038/nchembio.1890

Mehta, V., Thumar, J., and Singh, S. (2006). Production of alkaline protease from an alkaliphilic actinomycete. Bioresour. Technol. 97, 1650-1654. doi: 10.1016/j.biortech.2005.07.023

Metz, J. G., Roessler, P., Facciotti, D., Levering, C., Dittrich, F., Lassner, M., et al. (2001). Production of polyunsaturated fatty acids by polyketide synthases in both prokaryotes and eukaryotes. Science 293, 290-293. doi: 10.1126/ science. 1059593

Meyer, J. L., Jaekel, U., Tully, B. J., Glazer, B. T., Wheat, C. G., Lin, H.-T., et al. (2016). A distinct and active bacterial community in cold oxygenated fluids circulating beneath the western flank of the mid-Atlantic ridge. Sci. Rep. 6:22541. doi: 10.1038/srep22541

Moellering, R. C. Jr. (2006). Vancomycin: A 50-year reassessment. Arlington, VA, USA: The University of Chicago Press.

Moffitt, M. C., and Neilan, B. A. (2000). The expansion of mechanistic and organismic diversity associated with non-ribosomal peptides. FEMS Microbiol. Lett. 191, 159-167. doi: 10.1111/j.1574-6968.2000.tb09334.x

Moffitt, M. C., and Neilan, B. A. (2001). On the presence of peptide synthetase and polyketide synthase genes in the cyanobacterial genus Nodularia. FEMS Microbiol. Lett. 196, 207-214. doi: 10.1111/j.1574-6968.2001.tb10566.x

Moffitt, M. C., and Neilan, B. A. (2003). Evolutionary affiliations within the superfamily of ketosynthases reflect complex pathway associations. J. Mol. Evol. 56, 446-457. doi: 10.1007/s00239-002-2415-0

Montano, E. T., and Henderson, L. O. (2013). "Studies of antibiotic production by cave bacteria" in Cave microbiomes: A novel resource for drug discovery (New York, USA: Springer), 109-130.

Mootz, H. D., Schwarzer, D., and Marahiel, M. A. (2002). Ways of assembling complex natural products on modular nonribosomal peptide synthetases. Chembiochem 3, 490-504. doi: 10.1002/1439-7633(20020603)3:6<490::AIDCBIC490>3.0.CO;2-N

Morlon, H., O'connor, T. K., Bryant, J. A., Charkoudian, L. K., Docherty, K. M., Jones, E., et al. (2015). The biogeography of putative microbial antibiotic production. PloS One 10:e130659. doi: 10.1371/journal.pone.0130659

Morris, J. J. (2015). Black queen evolution: the role of leakiness in structuring microbial communities. Trends Genet. 31, 475-482. doi: 10.1016/j. tig.2015.05.004

Naganuma, T., Miyoshi, T., and Kimura, H. (2007). Phylotype diversity of deep-sea hydrothermal vent prokaryotes trapped by 0.2 -and $0.1-\mu \mathrm{m}$-pore-size filters. Extremophiles 11, 637-646. doi: 10.1007/s00792-007-0070-5

Nagrale, D. T., and Gawande, S. P. (2018). "Archaea: ecology, application, and conservation" in Microbial resource conservation (Switzerland: Springer), 431-451.

Nakaew, N., Pathom-Aree, W., and Lumyong, S. (2009). Generic diversity of rare actinomycetes from Thai cave soils and their possible use as new bioactive compounds. Actinomycetologica 23, 21-26. doi: 10.3209/saj.SAJ230201

Nam, Y. H., Choi, A., Hwang, J. M., Yim, K. J., Kim, J.-H., Choi, G.-G., et al. (2018). Paucibacter aquatile sp. nov. isolated from freshwater of the Nakdong River, Republic of Korea. Arch. Microbiol. 200, 877-882. doi: 10.1007/ s00203-018-1494-2 
Nandhini, S. U., Sudha, S., Jeslin, V. A., and Manisha, S. (2018). Isolation, identification and extraction of antimicrobial compounds produced by Streptomyces sps from terrestrial soil. Biocatal. Agric. Biotechnol. 15, 317-321. doi: 10.1016/j.bcab.2018.06.024

Nastro, L. J., and Finegold, S. M. (1972). Bactericidal activity of five antimicrobial agents against Bacteroides fragilis. J. Infect. Dis. 126, 104-107. doi: 10.1093/ infdis/126.1.104

Nastro, R., Di Costanzo, A., Gesuele, R., Trifuoggi, M., Inglese, M., and Guida, M. (2011). "Influence of temperature on the production of antibiotic molecules in Bacillus amyloliquefaciens strain HNA3" in Science against microbial pathogens: Communicating current research and technological advances (Badajoz: Formatex), 1307-1310.

Nett, M., Ikeda, H., and Moore, B. S. (2009). Genomic basis for natural product biosynthetic diversity in the actinomycetes. Nat. Prod. Rep. 26, 1362-1384. doi: $10.1039 / \mathrm{b} 817069 j$

Ningthoujam, D. S., Sanasam, S., and Nimaichand, S. (2009). Screening of actinomycete isolates from niche habitats in Manipur for antibiotic activity. Am. J. Biochem. Biotechnol. 5, 221-225. doi: 10.3844/ajbbsp.2009.221.225

Nithya, K., Muthukumar, C., Duraipandiyan, V., Dhanasekaran, D., and Thajuddin, N. (2015). Diversity and antimicrobial potential of culturable actinobacteria from desert soils of Saudi Arabia. J. Pharm. Sci. Res. 7, 117-122.

Northup, E., and Diana, K. H. L. (2001). Geomicrobiology of caves: a review. Geomicrobiol J. 18, 199-222. doi: 10.1080/01490450152467750

O'connor, E., and Shand, R. (2002). Halocins and sulfolobicins: the emerging story of archaeal protein and peptide antibiotics. J. Ind. Microbiol. Biotechnol. 28, 23-31. doi: 10.1038/sj/jim/7000190

Okada, B. K., and Seyedsayamdost, M. R. (2017). Antibiotic dialogues: induction of silent biosynthetic gene clusters by exogenous small molecules. FEMS Microbiol. Rev. 41, 19-33. doi: 10.1093/femsre/fuw035

Orcutt, B. N., Larowe, D. E., Biddle, J. F., Colwell, F. S., Glazer, B. T., Reese, B. K., et al. (2013). Microbial activity in the marine deep biosphere: progress and prospects. Front. Microbiol. 4:189. doi: 10.3389/fmicb.2013.00189

Orsi, W., Biddle, J. F., and Edgcomb, V. (2013a). Deep sequencing of subseafloor eukaryotic rRNA reveals active fungi across marine subsurface provinces. PLoS One 8:e56335. doi: 10.1371/journal.pone.0056335

Orsi, W. D. (2018). Ecology and evolution of seafloor and subseafloor microbial communities. Nat. Rev. Microbiol. 16, 671-683. doi: 10.1038/s41579-018-0046-8

Orsi, W. D., Edgcomb, V. P., Christman, G. D., and Biddle, J. F. (2013b). Gene expression in the deep biosphere. Nature 499, 205-208. doi: 10.1038/ nature 12230

Osburn, M. R., Larowe, D. E., Momper, L. M., and Amend, J. P. (2014). Chemolithotrophy in the continental deep subsurface: Sanford underground research facility (SURF), USA. Front. Microbiol. 5:610. doi: 10.3389/ fmicb.2014.00610

Ouchari, L., Boukeskasse, A., Bouizgarne, B., and Ouhdouch, Y. (2019). Antimicrobial potential of actinomycetes isolated from the unexplored hot Merzouga desert and their taxonomic diversity. Biol Open 8:bio035410. doi: 10.1242/bio.035410

Pancrace, C., Gugger, M., and Calteau, A. (2017). "Genomics of NRPS/PKS biosynthetic gene clusters in cyanobacteria" in Cyanobacteria: Omics and manipulation. Vol. 32 (Norfolk, UK: Caister Academic Press), 55-74.

Park, H. B., Kwon, H. C., Lee, C.-H., and Yang, H. O. (2009). Glionitrin a, an antibiotic- antitumor metabolite derived from competitive interaction between abandoned mine microbes. J. Nat. Prod. 72, 248-252. doi: 10.1021/ np800606e

Park, H. B., Lee, J. K., Lee, K. R., and Kwon, H. C. (2014). Angumycinones $\mathrm{A}$ and B, two new angucyclic quinones from Streptomyces sp. KMC004 isolated from acidic mine drainage. Tetrahedron Lett. 55, 63-66. doi: 10.1016/j. tetlet.2013.10.112

Passari, A. K., Chandra, P., Leo, V. V., Mishra, V. K., Kumar, B., and Singh, B. P. (2017). Production of potent antimicrobial compounds from Streptomyces cyaneofuscatus associated with fresh water sediment. Front. Microbiol. 8:68. doi: $10.3389 /$ fmicb. 2017.00068

Passari, A. K., Leo, V. V., Chandra, P., Kumar, B., Nayak, C., Hashem, A., et al. (2018). Bioprospection of actinobacteria derived from freshwater sediments for their potential to produce antimicrobial compounds. Microb. Cell Factories 17:68. doi: 10.1186/s12934-018-0912-0

Pathom-Aree, W., Stach, J. E., Ward, A. C., Horikoshi, K., Bull, A. T., and Goodfellow, M. (2006). Diversity of actinomycetes isolated from challenger deep sediment $(10,898 \mathrm{~m})$ from the Mariana trench. Extremophiles 10, 181-189. doi: 10.1007/s00792-005-0482-Z

Patin, N. V., Duncan, K. R., Dorrestein, P. C., and Jensen, P. R. (2016). Competitive strategies differentiate closely related species of marine actinobacteria. ISME J. 10, 478-490. doi: 10.1038/ismej.2015.128

Patti, G. J., Yanes, O., and Siuzdak, G. (2012). Innovation: metabolomics: the apogee of the omics trilogy. Nat. Rev. Mol. Cell Biol. 13, 263-269. doi: 10.1038/ nrm3314

Paul, A., and Banerjee, A. (1983). Determination of optimum conditions for antibiotic production by Streptomyces galbus. Folia Microbiol. 28, 397-405. doi: 10.1007/BF02879489

Pelludat, C., Rakin, A., Jacobi, C., Schubert, S., and Heesemann, J. (1998). The yersiniabactin biosynthetic gene cluster of Yersinia enterocolitica: organization and siderophore-dependent regulation. J. Bacteriol. 180, 538-546.

Peterson, L., and Shanholtzer, C. (1992). Tests for bactericidal effects of antimicrobial agents: technical performance and clinical relevance. Clin Microbiol. Rev. 5, 420-432. doi: 10.1128/CMR.5.4.420

Pheng, S., Lee, J. J., Eom, M. K., Lee, K. H., and Kim, S.-G. (2017). Paucibacter oligotrophus sp. nov., isolated from fresh water, and emended description of the genus Paucibacter. Int. J. Syst. Evol. Microbiol. 67, 2231-2235. doi: 10.1099/ijsem.0.001931

Prangishvili, D., Holz, I., Stieger, E., Nickell, S., Kristjansson, J. K., and Zillig, W. (2000). Sulfolobicins, specific proteinaceous toxins produced by strains of the extremely thermophilic archaeal genus Sulfolobus. J. Bacteriol. 182, 2985-2988. doi: 10.1128/JB.182.10.2985-2988.2000

Prosser, J. I. (2015). Dispersing misconceptions and identifying opportunities for the use of'omics' in soil microbial ecology. Nat. Rev. Microbiol. 13, 439-446. doi: 10.1038/nrmicro3468

Prosser, J. I., Bohannan, B. J., Curtis, T. P., Ellis, R. J., Firestone, M. K., Freckleton, R. P., et al. (2007). The role of ecological theory in microbial ecology. Nat. Rev. Microbiol. 5, 384-392. doi: 10.1038/nrmicro1643

Quintero, M., Velásquez, A., Jutinico, L., Jiménez-Vergara, E., Blandón, L., Martinez, K., et al. (2018). Bioprospecting from marine coastal sediments of Colombian Caribbean: screening and study of antimicrobial activity. J. Appl. Microbiol. 125, 753-765. doi: 10.1111/jam.13926

Raaijmakers, J. M., and Mazzola, M. (2012). Diversity and natural functions of antibiotics produced by beneficial and plant pathogenic bacteria. Annu. Rev. Phytopathol. 50, 403-424. doi: 10.1146/annurev-phyto-081211-172908

Raaijmakers, J. M., Vlami, M., and De Souza, J. T. (2002). Antibiotic production by bacterial biocontrol agents. Antonie Van Leeuwenhoek 81, 537-547. doi: 10.1023/A:1020501420831

Rai, A. N. (2018). "Cyanobacteria-fungal symbioses: the cyanolichens" in CRC handbook of symbiotic cyanobacteria (Boca Raton, FL, USA: CRC Press), 15-48.

Rajput, Y., Biswas, J., and Rai, V. (2012). Potentiality test in antimicrobial activity and antibiotic sensitivity of subterranean Streptomyces strains isolated from Kotumsar cave of India. Int. J. Biol. Chem. 6, 53-60. doi: 10.3923/ ijbc. 2012.53 .60

Ranieri, M. R., Whitchurch, C. B., and Burrows, L. L. (2018). Mechanisms of biofilm stimulation by subinhibitory concentrations of antimicrobials. Curr. Opin. Microbiol. 45, 164-169. doi: 10.1016/j.mib.2018.07.006

Raper, K. B., Alexander, D. F., and Coghill, R. D. (1944). Penicillin: II. Natural variation and penicillin production in Penicillium notatum and allied species 1, 2. J. Bacteriol. 48, 639-659.

Raytapadar, S., Datta, R., and Paul, A. (1995). Effects of some heavy metals on growth, pigment and antibiotic production by Streptomyces galbus. Acta Microbiol. Immunol. Hung. 42, 171-177

Read, A. F., and Woods, R. J. (2014). Antibiotic resistance management. Evol. Med. Public Heal. 2014:147. doi: 10.1093/emph/eou024

Reddy, B. V. B., Milshteyn, A., Charlop-Powers, Z., and Brady, S. F. (2014). eSNaPD: a versatile, web-based bioinformatics platform for surveying and mining natural product biosynthetic diversity from metagenomes. Chem. Biol. 21, 1023-1033. doi: 10.1016/j.chembiol.2014.06.007

Reese, B. K., Zinke, L. A., Sobol, M. S., Larowe, D. E., Orcutt, B. N., Zhang, X., et al. (2018). Nitrogen cycling of active bacteria within oligotrophic sediment of the mid-Atlantic ridge flank. Geomicrobiol J. 35, 468-483. doi: 10.1080/01490451.2017.1392649

Repka, S., Koivula, M., Harjunpä, V., Rouhiainen, L., and Sivonen, K. (2004). Effects of phosphate and light on growth of and bioactive peptide production 
by the cyanobacterium Anabaena strain 90 and its anabaenopeptilide mutant. Appl. Environ. Microbiol. 70, 4551-4560. doi: 10.1128/ AEM.70.8.4551-4560.2004

Rigali, S., Titgemeyer, F., Barends, S., Mulder, S., Thomae, A. W., Hopwood, D. A., et al. (2008). Feast or famine: the global regulator DasR links nutrient stress to antibiotic production by Streptomyces. EMBO Rep. 9, 670-675. doi: $10.1038 /$ embor. 2008.83

Riley, M. A., and Gordon, D. M. (1999). The ecological role of bacteriocins in bacterial competition. Trends Microbiol. 7, 129-133. doi: 10.1016/ S0966-842X(99)01459-6

Rodriguez-Valera, F., Juez, G., and Kushner, D. (1982). Halocins: salt-dependent bacteriocins produced by extremely halophilic rods. Can. J. Microbiol. 28, 151-154. doi: 10.1139/m82-019

Roller, L., and Gowan, J. (2016). Disease state management: antibiotic resistance. AJP 97, 64-72.

Rosenfeld, W. D., and Zobell, C. E. (1947). Antibiotic production by marine microorganisms. J. Bacteriol. 54, 393-398.

Röttig, M., Medema, M. H., Blin, K., Weber, T., Rausch, C., and Kohlbacher, O. (2011). NRPSpredictor2-a web server for predicting NRPS adenylation domain specificity. Nucleic Acids Res. 39, W362-W367. doi: 10.1093/nar/gkr323

Rowe, O. F., Sánchez-España, J., Hallberg, K. B., and Johnson, D. B. (2007). Microbial communities and geochemical dynamics in an extremely acidic, metal-rich stream at an abandoned sulfide mine (Huelva, Spain) underpinned by two functional primary production systems. Environ. Microbiol. 9, 1761-1771. doi: 10.1111/j.1462-2920.2007.01294.x

Rubin, B., and Tamaoki, J. (2000). Macrolide antibiotics as biological response modifiers. Curr. Opin. Investig. Drugs 2000, 169-172.

Saravanan, S., Sivakami, R., and Prem, G. (2015). Actinomycetes diversity in five fresh water systems of Pudukkottai, Tamilnadu and their antimicrobial activity. Int. J. Curr. Microbiol. App. Sci. 4, 672-677. doi: 10.1186/s12934-018-0912-0

Schatz, A., Bugle, E., and Waksman, S. A. (1944). Streptomycin, a substance exhibiting antibiotic activity against gram-positive and gram-negative bacteria*. Proc. Soc. Exp. Biol. Med. 55, 66-69. doi: 10.3181/00379727-55-14461

Schembri, M. A., Neilan, B. A., and Saint, C. P. (2001). Identification of genes implicated in toxin production in the cyanobacterium Cylindrospermopsis raciborskii. Environ. Toxicol. 16, 413-421. doi: 10.1002/tox.1051

Schippers, A., Bosecker, K., Willscher, S., Spröer, C., Schumann, P., and Kroppenstedt, R. M. (2002). Nocardiopsis metallicus sp. nov., a metal-leaching actinomycete isolated from an alkaline slag dump. Int. J. Syst. Evol. Microbiol. 52, 2291-2295. doi: 10.1099/00207713-52-6-2291

Schneider, O., Simic, N., Aachmann, F. L., Rückert, C., Kristiansen, K. A., Kalinowski, J., et al. (2018). Genome mining of Streptomyces sp. YIM 130001 isolated from lichen affords new thiopeptide antibiotic. Front. Microbiol. 9:3139. doi: $10.3389 /$ fmicb.2018.03139

Scholz, M. B., Lo, C.-C., and Chain, P. S. (2012). Next generation sequencing and bioinformatic bottlenecks: the current state of metagenomic data analysis. Curr. Opin. Biotechnol. 23, 9-15. doi: 10.1016/j.copbio.2011.11.013

Seitz, K. W., Lazar, C. S., Hinrichs, K.-U., Teske, A. P., and Baker, B. J. (2016). Genomic reconstruction of a novel, deeply branched sediment archaeal phylum with pathways for acetogenesis and sulfur reduction. ISME J. 10, 1696-1705. doi: 10.1038/ismej.2015.233

Selvin, J., Sathiyanarayanan, G., Lipton, A. N., Al-Dhabi, N. A., Valan Arasu, M., and Kiran, G. S. (2016). Ketide synthase (KS) domain prediction and analysis of iterative type II PKS gene in marine sponge-associated actinobacteria producing biosurfactants and antimicrobial agents. Front. Microbiol. 7:63. doi: $10.3389 /$ fmicb. 2016.00063

Senhorinho, G. N., Laamanen, C. A., and Scott, J. A. (2018). Bioprospecting freshwater microalgae for antibacterial activity from water bodies associated with abandoned mine sites. Phycologia 57, 432-439. doi: 10.2216/17-114.1

Ser, H.-L., Tan, W.-S., Ab Mutalib, N.-S., Yin, W.-F., Chan, K.-G., Goh, B.-H., et al. (2018). Genome sequence of Streptomyces mangrovisoli MUSC 149T isolated from intertidal sediments. Braz. J. Microbiol. 49, 13-15. doi: 10.1016/j. bjm.2017.01.013

Shama, G. (2009). Zones of inhibition? The transfer of information relating to penicillin in Europe during world war II. Adv. Appl. Microbiol. 69, 133-158. doi: 10.1016/S0065-2164(09)69005-5

Shand, R. F., and Leyva, K. J. (2007). "Peptide and protein antibiotics from the domain Archaea: halocins and sulfolobicins" in Bacteriocins (Berlin, Heidelberg, Germany: Springer), 93-109.
Shen, B. (2003). Polyketide biosynthesis beyond the type I, II and III polyketide synthase paradigms. Curr. Opin. Chem. Biol. 7, 285-295. doi: 10.1016/ S1367-5931(03)00020-6

Shendure, J., Balasubramanian, S., Church, G. M., Gilbert, W., Rogers, J., Schloss, J. A., et al. (2017). DNA sequencing at 40: past, present and future. Nature 550, 345-353. doi: 10.1038/nature24286

Sibanda, T., Mabinya, L. V., Mazomba, N., Akinpelu, D. A., Bernard, K., Olaniran, A. O., et al. (2010). Antibiotic producing potentials of three freshwater actinomycetes isolated from the eastern Cape Province of South Africa. Int. J. Mol. Sci. 11, 2612-2623. doi: 10.3390/ijms 11072612

Siegwald, L., Touzet, H., Lemoine, Y., Hot, D., Audebert, C., and Caboche, S. (2017). Assessment of common and emerging bioinformatics pipelines for targeted metagenomics. PLoS One 12:e0169563. doi: 10.1371/journal. pone. 0169563

Sieniawska, E., Swatko-Ossor, M., Sawicki, R., Skalicka-Woźniak, K., and Ginalska, G. (2017). Natural terpenes influence the activity of antibiotics against isolated Mycobacterium tuberculosis. Med. Princ. Pract. 26, 108-112. doi: $10.1159 / 000454680$

Silva-Stenico, M. E., Silva, C. S. P., Lorenzi, A. S., Shishido, T. K., Etchegaray, A., Lira, S. P., et al. (2011). Non-ribosomal peptides produced by Brazilian cyanobacterial isolates with antimicrobial activity. Microbiol. Res. 166, 161-175. doi: 10.1016/j.micres.2010.04.002

Sket, B. (1996). The ecology of anchihaline caves. Trends Ecol. Evol. 11, 221225. doi: 10.1016/0169-5347(96)20031-X

Skočibušić, M., Lacić, S., and Rašić, Z. (2019). Evaluation of antimicrobial potential of the marine Cyanobacterium, Rivularia mesenterica. J Adv Microbiol 16, 1-11. doi: 10.9734/jamb/2019/v16i430128

Smith, H. L., and Waltman, P. (1995). The theory of the chemostat: Dynamics of microbial competition. Cambridge, UK: Cambridge University Press.

Song, S., Gong, T., Yamasaki, R., Kim, J. S., and Wood, T. K. (2019). Identification of a potent indigoid persister antimicrobial by screening dormant cells. Biotechnol. Bioeng. 116, 2263-2274. doi: 10.1002/bit.27078

Song, Y., Tong, Z., Wang, J., Wang, L., Guo, Z., Han, Y., et al. (2004). Complete genome sequence of Yersinia pestis strain 91001, an isolate avirulent to humans. DNA Res. 11, 179-197. doi: 10.1093/dnares/11.3.179

Southam, C. M. (1943). Effects of extract of western red-cedar heartwood on certain wood-decaying fungi in culture. Phytopathology 33, 517-524.

Stanier, R., and Bazine, G. (1977). Phototrophic prokaryotes: the cyanobacteria. Annu. Rev. Microbiol. 31, 225-274. doi: 10.1146/annurev.mi.31.100177.001301

Staunton, J., and Weissman, K. J. (2001). Polyketide biosynthesis: a millennium review. Nat. Prod. Rep. 18, 380-416. doi: 10.1039/a909079g

Stebbing, A. (1982). Hormesis-the stimulation of growth by low levels of inhibitors. Sci. Total Environ. 22, 213-234. doi: 10.1016/0048-9697(82)90066-3

Stein, J. L., and Simon, M. I. (1996). Archaeal ubiquity. Proc. Natl. Acad. Sci. U. S. A. 93, 6228-6230. doi: 10.1073/pnas.93.13.6228

Stein, T. (2005). Bacillus subtilis antibiotics: structures, syntheses and specific functions. Mol. Microbiol. 56, 845-857. doi: 10.1111/j.1365-2958.2005.04587.x

Strohl, W. R. (2000). The role of natural products in a modern drug discovery program. Drug Discov. Today 5, 39-41. doi: 10.1016/S1359-6446(99)01443-9

Strohl, W. R. (2004). "Antimicrobials" in Microbial diversity and bioprospecting (American Society of Microbiology), 336-355.

Summers Engel, A., Kinkle, B. K., and Kane, T. C. (2001). Ecological assessment and geological significance of microbial communities from Cesspool Cave, Virginia. Geomicrobiol J. 18, 259-274. doi: 10.1080/01490450152467787

Swain, S. S., Paidesetty, S. K., and Padhy, R. N. (2017). Antibacterial, antifungal and antimycobacterial compounds from cyanobacteria. Biomed. Pharmacother. 90, 760-776. doi: 10.1016/j.biopha.2017.04.030

Tang, L., Shah, S., Chung, L., Carney, J., Katz, L., Khosla, C., et al. (2000). Cloning and heterologous expression of the epothilone gene cluster. Science 287, 640-642. doi: 10.1126/science.287.5453.640

Tenover, F. C. (2006). Mechanisms of antimicrobial resistance in bacteria. Am. J. Med. 119, S3-S10. doi: 10.1016/j.amjmed.2006.03.011

Thornburg, C. C., Zabriskie, T. M., and Mcphail, K. L. (2010). Deep-sea hydrothermal vents: potential hot spots for natural products discovery? J. Nat. Prod. 73, 489-499. doi: 10.1021/np900662k

Tillett, D., Dittmann, E., Erhard, M., Von Döhren, H., Börner, T., and Neilan, B. A. (2000). Structural organization of microcystin biosynthesis in Microcystis aeruginosa PCC7806: an integrated peptide-polyketide synthetase system. Chem. Biol. 7, 753-764. doi: 10.1016/S1074-5521(00)00021-1 
Tiwari, K., and Gupta, R. K. (2012). Rare actinomycetes: a potential storehouse for novel antibiotics. Crit. Rev. Biotechnol. 32, 108-132. doi: 10.3109/ 07388551.2011 .562482

Torsvik, V., and Øvreås, L. (2002). Microbial diversity and function in soil: from genes to ecosystems. Curr. Opin. Microbiol. 5, 240-245. doi: 10.1016/ S1369-5274(02)00324-7

Tsai, S.-C. (2018). The structural enzymology of iterative aromatic polyketide synthases: a critical comparison with fatty acid synthases. Annu. Rev. Biochem. 87, 503-531. doi: 10.1146/annurev-biochem-063011-164509

Twing, K. I., Brazelton, W. J., Kubo, M. D., Hyer, A. J., Cardace, D., Hoehler, T. M., et al. (2017). Serpentinization-influenced groundwater harbors extremely low diversity microbial communities adapted to high pH. Front. Microbiol. 8:308. doi: 10.3389/fmicb. 2017.00308

Tyc, O., Song, C., Dickschat, J. S., Vos, M., and Garbeva, P. (2017). The ecological role of volatile and soluble secondary metabolites produced by soil bacteria. Trends Microbiol. 25, 280-292. doi: 10.1016/j.tim.2016.12.002

Valli, S., Suvathi, S. S., Aysha, O., Nirmala, P., Vinoth, K. P., and Reena, A. (2012). Antimicrobial potential of Actinomycetes species isolated from marine environment. Asian Pac. J. Trop. Biomed. 2, 469-473. doi: 10.1016/S2221-1691(12)60078-1

Van Der Heul, H. U., Bilyk, B. L., Mcdowall, K. J., Seipke, R. F., and Van Wezel, G. P. (2018). Regulation of antibiotic production in Actinobacteria: new perspectives from the post-genomic era. Nat. Prod. Rep. 35, 575-604. doi: 10.1039/C8NP00012C

Van Der Meij, A., Worsley, S. F., Hutchings, M. I., and Van Wezel, G. P. (2017). Chemical ecology of antibiotic production by actinomycetes. FEMS Microbiol. Rev. 41, 392-416. doi: 10.1093/femsre/fux005

Van Lanen, S. G., and Shen, B. (2006). Microbial genomics for the improvement of natural product discovery. Curr. Opin. Microbiol. 9, 252-260. doi: 10.1016/j. mib.2006.04.002

Van Wezel, G. P., and Mcdowall, K. J. (2011). The regulation of the secondary metabolism of Streptomyces: new links and experimental advances. Nat. Prod. Rep. 28, 1311-1333. doi: 10.1039/c1np00003a

Ventola, C. L. (2015). The antibiotic resistance crisis: part 1: causes and threats. Pharmacy and Therapeutics 40, 277-283.

Vijayakumari, S. J., Sasidharannair, N. K., Nambisan, B., and Mohandas, C. (2013). Optimization of media and temperature for enhanced antimicrobial production by bacteria associated with Rhabditis sp. Iranian J. Microbiol. 5, 136-141.

Vogelman, B., and Craig, W. A. (1986). Kinetics of antimicrobial activity. J. Pediatr. 108, 835-840. doi: 10.1016/S0022-3476(86)80754-5

Voo, Z. X., Khan, M., Xu, Q., Narayanan, K., Ng, B. W., Ahmad, R. B., et al. (2016). Antimicrobial coatings against biofilm formation: the unexpected balance between antifouling and bactericidal behavior. Polym. Chem. 7, 656-668. doi: 10.1039/C5PY01718A

Walsh, C. (2000). Molecular mechanisms that confer antibacterial drug resistance. Nature 406, 775-781. doi: 10.1038/35021219

Walsh, C. T. (2016). Insights into the chemical logic and enzymatic machinery of NRPS assembly lines. Nat. Prod. Rep. 33, 127-135. doi: 10.1039/C5NP00035A

Wang, J. M., Johnston, P. B., Ball, B. G., and Brinton, R. D. (2005). The neurosteroid allopregnanolone promotes proliferation of rodent and human neural progenitor cells and regulates cell-cycle gene and protein expression. J. Neurosci. 25, 4706-4718. doi: 10.1523/JNEUROSCI.4520-04.2005

Wang, Y., Fang, X., Cheng, Y., and Zhang, X. (2011). Manipulation of pH shift to enhance the growth and antibiotic activity of Xenorhabdus nematophila. Biomed. Res. Int. 2011:672369. doi: 10.1155/2011/672369

Weber, T., Charusanti, P., Musiol-Kroll, E. M., Jiang, X., Tong, Y., Kim, H. U., et al. (2015). Metabolic engineering of antibiotic factories: new tools for antibiotic production in actinomycetes. Trends Biotechnol. 33, 15-26. doi: 10.1016/j.tibtech.2014.10.009

Weinberg, E. D. (1990). Roles of trace metals in transcriptional control of microbial secondary metabolism. Biol. Met. 2, 191-196. doi: 10.1007/BF01141358

Weissman, K. J. (2009). Introduction to polyketide biosynthesis. Methods Enzymol. 459, 3-16. doi: 10.1016/S0076-6879(09)04601-1

Weissman, K. J. (2015). The structural biology of biosynthetic megaenzymes. Nat. Chem. Biol. 11, 660-670. doi: 10.1038/nchembio.1883

Weissman, K. J., and Müller, R. (2008). Protein-protein interactions in multienzyme megasynthetases. Chembiochem 9, 826-848. doi: 10.1002/cbic.200700751

Wells, I. C. (1952). Antibiotic substances produced by Pseudomonas aeruginosa. Syntheses of Pyo Ib, Pyo Ic, and Pyo III. J. Biol. Chem. 196, 331-340
Wenzel, S. C., and Müller, R. (2005a). Formation of novel secondary metabolites by bacterial multimodular assembly lines: deviations from textbook biosynthetic logic. Curr. Opin. Chem. Biol. 9, 447-458. doi: 10.1016/j.cbpa.2005.08.001

Wenzel, S. C., and Müller, R. (2005b). Recent developments towards the heterologous expression of complex bacterial natural product biosynthetic pathways. Curr. Opin. Biotechnol. 16, 594-606. doi: 10.1016/j.copbio.2005.10.001

Whyte, L., Slagman, S., Pietrantonio, F., Bourbonniere, L., Koval, S., Lawrence, J., et al. (1999). Physiological adaptations involved in alkane assimilation at a low temperature by Rhodococcus sp. strain Q15. Appl. Environ. Microbiol. 65, 2961-2968

Williams, S., Davies, F., Mayfield, C., and Khan, M. (1971). Studies on the ecology of actinomycetes in soil II. The $\mathrm{pH}$ requirements of streptomycetes from two acid soils. Soil Biol. Biochem. 3, 187-195. doi: 10.1016/0038-0717(71)90014-9

Williams, S., and Vickers, J. (1986). The ecology of antibiotic production. Microb. Ecol. 12, 43-52. doi: 10.1007/BF02153221

Williamson, J. M., Inamine, E., Wilson, K. E., Douglas, A. W., Liesch, J. M., and Albers-Schönberg, G. (1985). Biosynthesis of the beta-lactam antibiotic, thienamycin, by Streptomyces cattleya. J. Biol. Chem. 260, 4637-4647.

Woon, S.-A., and Fisher, D. (2016). Antimicrobial agents-optimising the ecological balance. BMC Med. 14:114. doi: 10.1186/s12916-016-0661-z

Wright, J. M. (1956). The production of antibiotics in soil. Ann. Appl. Biol. 44, 461-466. doi: 10.1111/j.1744-7348.1956.tb02140.x

Yang, S.-C., Lin, C.-H., Sung, C. T., and Fang, J.-Y. (2014). Antibacterial activities of bacteriocins: application in foods and pharmaceuticals. Front. Microbiol. 5:241. doi: $10.3389 /$ fmicb. 2014.00688

Yim, G., Wang, H. H., and Frs, J. D. (2007). Antibiotics as signalling molecules. Philos. Trans. Royal S. Lond. B Biol. Sci. 362, 1195-1200. doi: 10.1098/ rstb.2007.2044

Yu, D., Xu, F., Zeng, J., and Zhan, J. (2012). Type III polyketide synthases in natural product biosynthesis. IUBMB Life 64, 285-295. doi: 10.1002/iub.1005

Yu, W., Hallinen, K. M., and Wood, K. B. (2018). Interplay between antibiotic efficacy and drug-induced lysis underlies enhanced biofilm formation at subinhibitory drug concentrations. Antimicrob. Agents Chemother. 62, e01603e01617. doi: 10.1128/AAC.01603-17

Yücel, S., and Yamaç, M. (2010). Selection of Streptomyces isolates from Turkish karstic caves against antibiotic resistant microorganisms. Pak. J. Pharm. Sci. 23, 1-6.

Zeppilli, D., Leduc, D., Fontanier, C., Fontaneto, D., Fuchs, S., Gooday, A. J., et al. (2018). Characteristics of meiofauna in extreme marine ecosystems: a review. Mar. Biodivers. 48, 35-71. doi: 10.1007/s12526-017-0815-Z

Zerikly, M., and Challis, G. L. (2009). Strategies for the discovery of new natural products by genome mining. Chembiochem 10, 625-633. doi: 10.1002/ cbic. 200800389

Zhang, C., Naman, C., Engene, N., and Gerwick, W. (2017). Laucysteinamide a, a hybrid PKS/NRPS metabolite from a Saipan Cyanobacterium, cf. Caldora penicillata. Mar. Drugs 15:121. doi: 10.3390/md15040121

Zhang, D., De Souza, R. F., Anantharaman, V., Iyer, L. M., and Aravind, L. (2012a). Polymorphic toxin systems: comprehensive characterization of trafficking modes, processing, mechanisms of action, immunity and ecology using comparative genomics. Biol. Direct 7:18. doi: 10.1186/1745-6150-7-18

Zhang, J., Yang, Y., Zhao, L., Li, Y., Xie, S., and Liu, Y. (2015). Distribution of sediment bacterial and archaeal communities in plateau freshwater lakes. Appl. Microbiol. Biotechnol. 99, 3291-3302. doi: 10.1007/s00253-014-6262-x

Zhang, L.-M., Hu, H.-W., Shen, J.-P., and He, J.-Z. (2012b). Ammonia-oxidizing archaea have more important role than ammonia-oxidizing bacteria in ammonia oxidation of strongly acidic soils. ISME J. 6, 1032-1045. doi: 10.1038/ismej.2011.168

Zhang, W., Li, F., and Nie, L. (2010). Integrating multiple 'omics' analysis for microbial biology: application and methodologies. Microbiology 156, 287-301. doi: 10.1099/mic.0.034793-0

Zhu, H., Sandiford, S. K., and Van Wezel, G. P. (2014). Triggers and cues that activate antibiotic production by actinomycetes. J. Ind. Microbiol. Biotechnol. 41, 371-386. doi: 10.1007/s10295-013-1309-Z

Ziemert, N., Alanjary, M., and Weber, T. (2016). The evolution of genome mining in microbes-a review. Nat. Prod. Rep. 33, 988-1005. doi: 10.1039/ C6NP00025H

Ziemert, N., Podell, S., Penn, K., Badger, J. H., Allen, E., and Jensen, P. R. (2012). The natural product domain seeker NaPDoS: a phylogeny based 
bioinformatic tool to classify secondary metabolite gene diversity. PLoS One 7:e34064. doi: 10.1371/journal.pone.0034064

Zinke, L. A., Mullis, M. M., Bird, J. T., Marshall, I. P., Jørgensen, B. B., Lloyd, K. G., et al. (2017). Thriving or surviving? Evaluating active microbial guilds in Baltic Sea sediment. Environ. Microbiol. Rep. 9, 528-536. doi: $10.1111 / 1758-2229.12578$

Zothanpuia, A. K. P., Gupta, V. K., and Singh, B. P. (2016). Detection of antibiotic-resistant bacteria endowed with antimicrobial activity from a freshwater lake and their phylogenetic affiliation. PeerJ 4:e2103. doi: 10.7717/ peerj. 2103
Conflict of Interest: The authors declare that the research was conducted in the absence of any commercial or financial relationships that could be construed as a potential conflict of interest.

Copyright (C) 2019 Mullis, Rambo, Baker and Reese. This is an open-access article distributed under the terms of the Creative Commons Attribution License (CC BY). The use, distribution or reproduction in other forums is permitted, provided the original author(s) and the copyright owner(s) are credited and that the original publication in this journal is cited, in accordance with accepted academic practice. No use, distribution or reproduction is permitted which does not comply with these terms. 